\title{
ANÁLISE DA EVOLUÇ̃̃O TEMPORAL DO USO E COBERTURA DA TERRA NA BACIA DO RIBEIRÃO DA LAJE, NO SUDOESTE DE GOIÁS, DE 1987 A 2017
}

\author{
Wellmo dos Santos Alves \\ Instituto Federal Goiano - Campus Rio Verde \\ wellmoagro2@gmail.com \\ Alécio Perini Martins \\ Universidade Federal de Jataí \\ alecioperini@yahoo.com.br \\ Iraci Scopel \\ Universidade Federal de Jataí \\ iraciscopel@gmail.com
}

\begin{abstract}
RESUMO
O modelo de produção, principalmente a partir da revolução industrial, muitas vezes sem considerar a conservação dos recursos naturais para atender à demanda de uma população mundial crescente, tem causado desequilíbrios ecológicos (perda da biodiversidade, impactos negativos nos solos e recursos hídricos, entre outros). Assim, objetivou-se entender as mudanças do uso e cobertura da terra na bacia do ribeirão da Laje, de 1987 a 2017. Esse recurso é importante para diversos usos múltiplos na microrregião Sudoeste de Goiás, sendo uma das principais fontes de água para o abastecimento público da população de Rio Verde (GO). Com o uso de geotecnologias, foram gerados os produtos cartográficos e obtidos dados quantitativos, estes analisados utilizando a técnica de matriz de transição. Foram observados, principalmente: substituição significativa de pastagem por área de agricultura; diminuição da vegetação de Cerrado; expansão da área urbana, industrial, de construção rural e represas; e extensas áreas com erosão laminar e em sulco, principalmente associadas à pastagem degradada. Esses dados indicam a necessidade de políticas públicas comprometidas com o desenvolvimento econômico condizente com a sustentabilidade ambiental. Esse trabalho irá subsidiar o planejamento e a gestão ambiental dessa bacia hidrográfica e servirá de base para outros estudos.
\end{abstract}

Palavras-chave: Geotecnologias. Planejamento ambiental. Recursos hídricos.

\section{ANALYSIS OF TEMPORAL EVOLUTION OF LAND USE AND COVERAGE IN THE WATERSHED OF RIBEIRÃO DA LAJE, IN THE SOUTHWEST OF GOIÁS STATE, FROM 1987 TO 2017}

\begin{abstract}
The production model, mainly from the Industrial Revolution, many times regardless of the natural resources conservation to meet the demand of a worldwide increasing population, has caused ecological imbalances (biodiversity loss, negative impacts on the soils and water resources, and the like). Thus, it was an objective to understand the changes in land use and land coverage in the watershed of Ribeirão da Laje, from 1987 to 2017 . This resource is important to several multiple uses in the micro region of the Southwest of Goiás state, being considered one of the main water sources to the public supply of the urban population of Rio Verde (GO). With the use of geotechnologies, cartographic products were generated and quantitative data obtained, analyzed through the use of the transition matrix technique. It was observed, mainly: a significant replacement of the pasture by agricultural area; decrease of Cerrado's vegetation; the expansion of the urban, industrial, rural and dams construction; and extensive areas with laminar erosion and in groove, mainly related to degraded landscapes. These data indicate the necessity of public policies committed to the economical development consistent with the environmental sustainability. This paper will subsidize the planning and environmental management of this watershed and will serve as a base to further studies.
\end{abstract}

Keywords: Geotechnologies. Environmental planning. Water resources.

\begin{tabular}{|c|c|}
\hline & Uberlândia-MG \\
\hline
\end{tabular}




\title{
INTRODUÇÃO
}

A população mundial, de 7,6 bilhões de pessoas em 2017, cresce quase 83 milhões a cada ano, com estimativa para 8,6 bilhões em 2030, 9,8 bilhões em 2050 e que supere os 11,2 bilhões em 2100 (ONUBR, 2017). O Brasil apresentou uma população estimada de 207,70 milhões de pessoas em 2017 (IBGE, 2018a), a quinta maior do mundo (UN, 2017), com crescimento populacional expressivo até 2042 , ano em que a população estimada será de 228,40 milhões de pessoas (IBGE, 2013). O estado de Goiás apresenta uma população estimada de 6,80 milhões de pessoas (IBGE, 2018b), a 14 a maior do Brasil (IBGE, 2017), com estimativa de 7,02 milhões em 2020, 7,40 milhões em 2025 e 7,71 milhões em 2030 (IBGE, 2013). Esses dados indicam que a demanda mundial, assim como no Brasil e no estado de Goiás, por habitação, alimentos, recursos naturais e outros, também aumentará, sendo necessárias políticas públicas para que essas demandas sejam atendidas com menor impacto possível ao meio ambiente.

Destaque na produção agropecuária mundial, o Brasil é um dos países onde há maior diversidade de ecossistemas e maior disponibilidade de água doce, entretanto, a oferta de água potável em algumas regiões brasileiras vem se tornando um fator limitante em virtude de aspectos climáticos e, inclusive, de impactos ambientais causados a esse recurso essencial para a vida na Terra (FERNANDES et al., 2014).

No cenário encontrado no Sudoeste de Goiás até a década de 1950, os modos de vida e produção eram semelhantes aos do século XIX. A partir dessa década, muitas transformações ocorreram nesse ambiente, principalmente a partir da década de 1970 (MARTINS et al., 2016). A partir da década de 1970, o Cerrado tornou-se um dos principais focos de programas de desenvolvimento e expansão da agropecuária no interior do Brasil com a criação do Centro de Pesquisa Agropecuária do Cerrado (CPAC) da EMBRAPA e o lançamento de programas governamentais para o desenvolvimento dos Cerrados, entre estes, o Programa Nipo-Brasileiro para o Desenvolvimento do Cerrado (PRODECER), em parceria com a Agência Japonesa de Cooperação Internacional, e o Programa Para o Desenvolvimento do Cerrado (POLOCENTRO) (PESSÔA, 1988). Nessa região, o principal agente transformador do meio rural foi a tecnologia, representada pelas modernas técnicas de manejo e controle da produção, possibilitando a obtenção de mais de uma safra por ano, com altos índices de produtividade; sendo que as construções e pavimentação de rodovias e o investimento do Governo Federal em programas de ocupação e produção agropecuária nas regiões Norte e CentroOeste colocaram o Sudoeste de Goiás no mapa econômico do Brasil (MARTINS et al., 2016).

Esse intenso processo de uso e cobertura das terras nas áreas de Cerrado, intensificado a partir da década de 1950, com os planos de ocupação da área central do Brasil, levou a substituição de extensas áreas de vegetação natural por monoculturas e demais usos em prol do agronegócio (SOUZA et al., 2014), e, associado ao uso e manejo inadequados dos solos, causa impactos negativos ao meio ambiente (como assoreamento e contaminação dos recurso hídricos, perda da biodiversidade, desequilíbrios em ecossistemas e outros danos).

O ser humano é o principal ator da transformação do seu habitat, resultando em problemas e perdas das mais diversas proporções ao meio ambiente, sendo muitos desses danos considerados irreversíveis (ALMEIDA et al., 2017). Os ciclos e processos naturais transformam continuamente matéria e energia, renovando e mantendo as condições necessárias à existência da vida na Terra. No entanto, as alterações provocadas no meio físico pelo homem têm preponderado a diversos impactos ambientais (FERNANDES et al., 2014).

O uso do solo refere-se ao modo como a terra é usada pelos seres humanos, e a cobertura da terra, à distribuição dos elementos biofísicos no espaço geográfico (SEABRA et al., 2014). Conforme (BRAZ et al., 2017, p. 2),

\begin{abstract}
Bacias hidrográficas e principalmente os corpos d'água são sobretudo passíveis de transtornos por conta de mudanças generalizadas no uso e cobertura da terra. Antes da interferência humana, os sistemas hidrográficos estão geralmente em uma condição que se aproxima de um estado de equilíbrio. Por isso, todas as interferências devem ser realizadas de maneira racional, considerando sempre a conservação da natureza, e para isso, o manejo da terra tem estabelecido planos ideais para a racionalização dos usos visando a conservação, principalmente em bacias hidrográficas no meio rural
\end{abstract}

Assim, a análise do uso e cobertura da terra é fundamental para estudos ambientais, pois representa as pressões e impactos sobre os elementos naturais presentes na paisagem (SEABRA et al., 2014).

\begin{tabular}{llllll}
\hline Caminhos de Geografia & Uberlândia-MG & v. 21, n. 74 & Abr/2020 & p. 01-20 & Página 2
\end{tabular}


As geotecnologias (geoprocessamento, sensoriamento remoto, GPS, cartografia automatizada, Sistema de Informação Geográfica - SIG) possibilitam analisar o meio ambiente de forma a entender como questões relacionadas às alterações ambientais se comportam no espaço (ROSA, 2005). Dentre as ferramentas utilizadas atualmente para a compreensão dos organismos terrestres e das ações do homem sobre o mesmo está o sensoriamento remoto e o geoprocessamento (FERNANDES et al., 2014), que podem ser usadas nos estudos de bacias hidrográficas, possibilitando a obtenção de resultados representativos, de forma rápida e econômica. As técnicas de interpretação de imagens de satélite auxiliam na avaliação da superfície terrestre, sobretudo aspectos de ordem espacial e temporal (MARANHÃO et al., 2017).

Assim, objetivou-se mapear e analisar as mudanças do uso e cobertura da terra na bacia do ribeirão da Laje, nas últimas três décadas. Essa unidade hidrográfica foi escolhida como objeto deste estudo por ser uma das principais fontes fornecedoras de água para o abastecimento público da população urbana do município de Rio Verde (principal município do Sudoeste de Goiás, com a quarta maior população do estado), fornece, segundo dados disponibilizados pela empresa de Saneamento de Goiás (SANEAGO), de 100 a 110 L.s. $^{-1}$, além de ser importante fonte de água para outros usos múltiplos nesse município e nos munícipios de Santa Helena de Goiás e Santo Antônio da Barra, no Sudoeste de Goiás. É importante ressaltar, ainda, que não há estudo com essa temática na área de contribuição do referido corpo hídrico, sendo este trabalho importante para subsidiar ações que visem a garantia de água em quantidade e qualidade para atender aos usos múltiplos na unidade territorial em questão.

Conforme dados observados no Sistema Nacional de Informação sobre Saneamento (SNIS, 2018), a média de consumo de água em Rio Verde (GO) é de 147,1 litros/habitante/dia, ou seja, o volume de água captado no ribeirão da Laje atende aproximadamente 55.798,78 habitantes/dia, que corresponde a $25,71 \%$ da população rio-verdense, sendo esta de 217.048 habitantes (IBGE, 2018c). A outra parte da população é abastecida por águas captadas no ribeirão das Abóboras, principalmente, e em fontes subterrâneas.

É importante ressaltar que a mudança do uso e cobertura da terra pode interferir na produção/disponibilização de água para consumo. O cenário em uma área com maior quantidade de vegetação nativa é diferente do cenário de uma área com intenso uso agropecuário, pois a mudança na ocupação altera padrões de infiltração, escoamento e outros.

\section{MATERIAL E MÉTODOS}

Inicialmente, foram realizadas leituras de diversos trabalhos publicados sobre estudos do uso e cobertura da terra. A partir dessas leituras, decidiu-se utilizar a proposta de Pontius Jr. et al. (2004), ou seja, a técnica de matriz de transição, assim como observado nos trabalhos de Fernandes et al. (2014), Oliveira et al. (2015), Campos e Queiroz Filho (2017). Em seguida, as atividades foram divididas em cinco etapas: obtenção das bases de dados (primeira etapa), localização e caracterização geral da área de estudo (segunda etapa), processamento digital (terceira etapa), validação dos produtos digitais (quarta etapa), análise de dados (quinta etapa).

O processamento digital das bases de dados foi realizado no ArcGIS $10.1^{\circledR}$, com licença de uso para o laboratório de Geoinformação da Universidade Federal de Goiás (UFG)/Regional Jataí.

\section{OBTENÇÃO DAS BASES DE DADOS (PRIMEIRA ETAPA)}

As bases de dados geográficos em escala pequena para a caracterização geral da bacia hidrográfica e estudo das mudanças do uso e cobertura da terra foram:

a) Imagem Shuttle Radar Topography Mission (SRTM), com resolução espacial de $30 \mathrm{~m} \times 30 \mathrm{~m}$, da órbita/ponto 223/72, gerada pela cooperação entre National Aeronautics and Space Administration (NASA) e a National Imagery and Mapping Agency (NIMA), do DOD (Departamento de Defesa) dos Estados Unidos da América e das agências espaciais da Alemanha e Itália e disponibilizada pelo United States Geological Survey (USGS, 2017);

b) Base cartográfica vetorial contínua, formato shapefile (shp) do estado de Goiás e do Distrito Federal (BC100/GO_DF) na escala 1:100.000, geração 06/06/2017, pelo convênio firmado entre o Instituto Mauro Borges de Estatística e Estudos Socioeconômicos (IMB)/Secretaria de Estado de Gestão e Planejamento (SEGPLAN) de Goiás e o IBGE, disponibilizada pelo SIEG (2017);

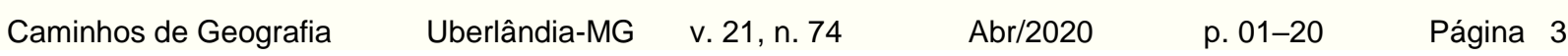


c) Mapa Geológico do Estado de Goiás e Distrito Federal, na escala 1:500.000, formato shp, geração de 13 de abril de 2009, pela Superintendência de Geologia e Mineração/Secretaria Estadual de Indústria e Comércio (SGM/SIC), e disponibilizado pelo Sistema Estadual de Geoinformação de Goiás (SIEG, 2017);

d) Mapa de Solos do Plano Diretor da Bacia do Rio Paranaíba, na escala 1:250.000, formato shp, geração 01 de março de 2005, pela Universidade Federal de Viçosa (UFV)/Fundação Rural Minas (Ruralminas); modelagem, alimentação do SIG e edição das cartas pela Superintendência de Geologia e Mineração/Secretaria estadual de Indústria e Comércio de Goiás (SGM/SIC), disponibilizado pelo SIEG (2017);

e) Imagens da órbita/ponto 223/72, com resolução espacial de $30 \mathrm{~m} \times 30 \mathrm{~m}$, de 20 de julho de 1987, 15 de julho de 1997, 25 de junho de 2007 e 6 de julho de 2017; sendo as imagens dos 3 primeiros anos do satélite Landsat 5/Sensor TM, e a do último ano, do Satélite Landsat 8/Sensor OLI, todas geradas pela National Aeronautics and Space Administration (NASA) e obtidas no catálogo de imagens do USGS (2017);

f) Rede de drenagens da base cartográfica vetorial digital atualizada do produto BC100/GO_DF, produzido pelo Instituto Brasileira de Geografia e Estatística (IBGE) na escala de 1:100.000, disponibilizada, em formato shp, pelo SIEG (2017).

\section{LOCALIZAÇÃO E CARACTERIZAÇÃO GERAL DA ÁREA DE ESTUDO (SEGUNDA ETAPA)}

A partir da base SRTM foram extraídas curvas de nível com equidistância de $5 \mathrm{~m}$. A partir das curvas de nível foi gerado um arquivo shp de delimitação da área da bacia, desenhada a partir da seção fluvial do exutório, ou seja, do ponto mais baixo, em direção ao divisor de águas. Com o uso desse arquivo shp e a partir de bases em escalas pequenas supracitadas foram organizados os mapas georreferenciados de localização, geológico, pedológico, hipsométrico e de declividade, possibilitando realizar a localização precisa e caracterização geral da área de estudo.

A bacia do ribeirão da Laje está localizada no Sudoeste de Goiás, conforme Figura 1.

Figura 1 - Localização da bacia hidrográfica do ribeirão da Laje (GO)

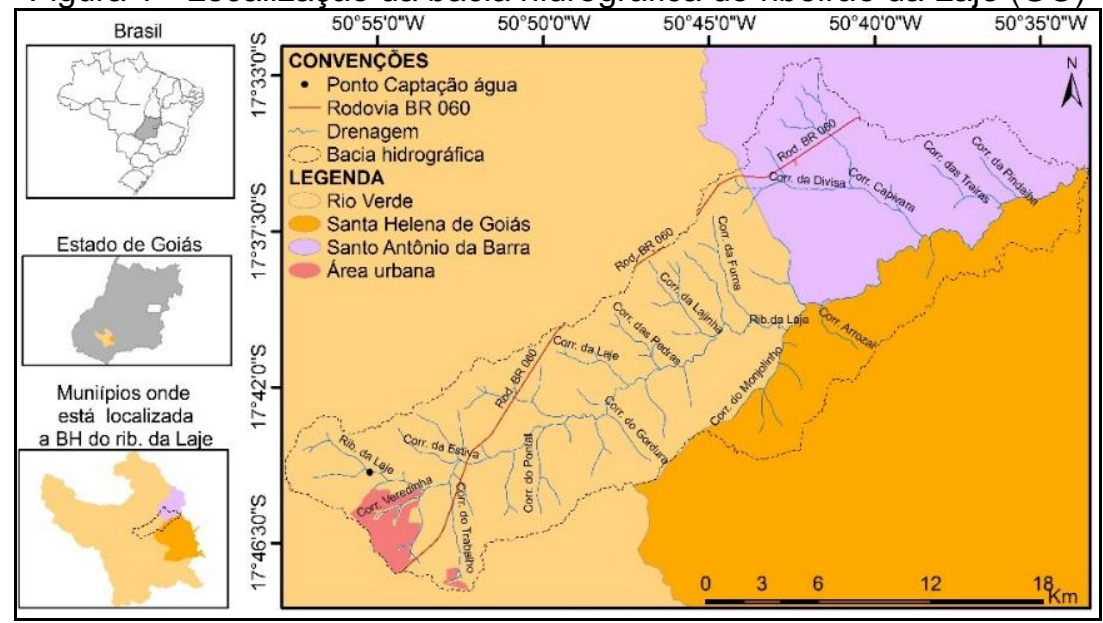

Fonte - Organizado pelos autores a partir de bases de dados disponibilizadas pelo SIEG (2017).

O ribeirão da Laje tem sua nascente principal no local com altitude e coordenadas geográficas aproximadas de $810 \mathrm{~m}$ e $50^{\circ} 56^{\prime} 32,449^{\prime \prime} \mathrm{W} / 17^{\circ} 43^{\prime} 17,873^{\prime \prime} \mathrm{S}$, respectivamente, e a sua foz está localizada na cota e coordenadas geográficas aproximadas de $525 \mathrm{~m}$ e $50^{\circ} 33^{\prime} 51,186 " \mathrm{~W} / 17^{\circ} 35^{\prime} 40,462$ "S, na ordem em que aparecem, na margem direita do Rio Verde, inserido na Bacia Hidrográfica do Rio Paranaíba. Com área total de 431,55 km², apresenta 249,62 $\mathrm{km}^{2}(57,84 \%), 112,98 \mathrm{~km}^{2}(26,18 \%)$ e $68,95 \mathrm{~km}^{2}(15,98 \%)$ dentro, respectivamente, dos municípios de Rio Verde (principal município da região e a quarta economia do estado), Santo Antônio da Barra e Santa Helena de Goiás.

Destacam-se como principais afluentes do ribeirão da Laje: córrego da Pindaíba, córrego Traíra, córrego Capivara, córrego da Divisa, córrego Arrozal, córrego da Furna, córrego do Monjolinho,

\begin{tabular}{llllll}
\hline Caminhos de Geografia & Uberlândia-MG & v. 21, n. 74 & Abr/2020 & p. 01-20 & Página 4
\end{tabular}


córrego da Lajinha, córrego das Pedras, córrego da Laje, córrego do Gordura, córrego Taperão, córrego do Pontal, córrego da Estiva, córrego do Trabalho e córrego Veredinha (Figura 1).

Na Figura 2 são apresentadas as formas geológicas, solos, declividade e hipsometria da bacia do ribeirão da Laje.

Figura 2 - Formações geológicas (A), solos (B), declividade (C) e hipsometria (D) da área de estudo

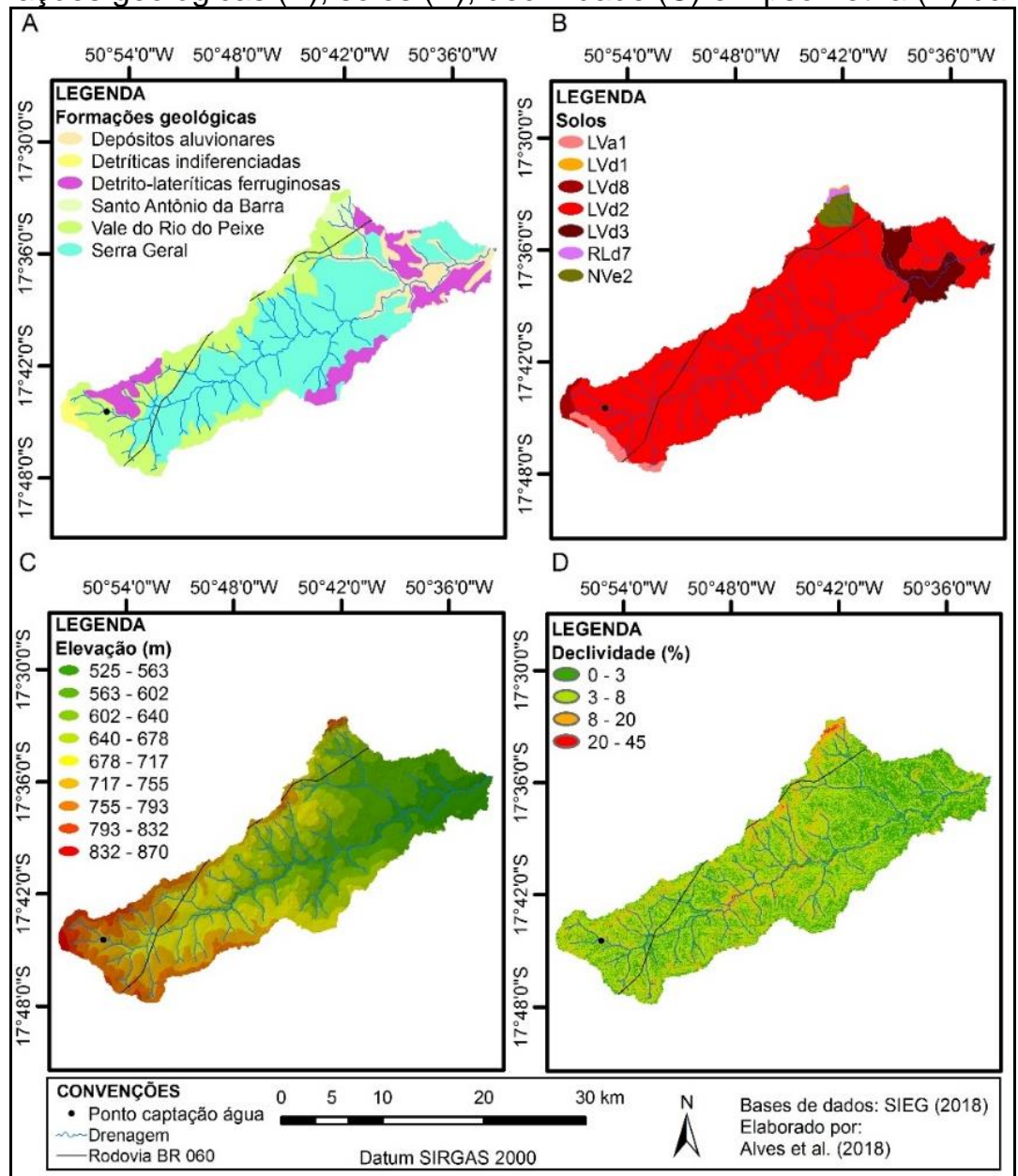

Fonte - Elaborado pelos autores, nas coordenadas geográficas, Datum Sirgas 2000, a partir de bases de dados disponibilizadas pelo SIEG (2017) e USGS (2017).

Inserida no Planalto Setentrional da Bacia Sedimentar do Paraná a bacia do ribeirão da Laje apresenta rochas de idades entre o Cretáceo e o Neogeno, as quais são apresentadas em seguida com respectivos litotipos e percentual em relação à área total da unidade territorial de estudo: Formação Serra Geral (basalto e basalto-andesito), 52,48\%; Vale do Rio do Peixe (arenito e argilito arenoso), 23,30\%; cobertura detrito-lateríticas ferruginosas (aglomerado, laterita, argilita e areia), 12,47\%; depósito aluvionares (depósitos de areia e depósitos de cascalho), 8,79\%; Santo Antônio da Barra, 1,88\%; e coberturas detríticas indiferenciadas (depósitos de areia, depósitos de cascalho, depósitos de argila), 1,08\% (Figura 2 A), conforme base de dados disponibilizada pelo SIEG (2017).

Quanto ao material pedológico, apresenta as seguintes classes de solos com respectivo relevo e percentual em relação á área total da bacia hidrográfica: Latossolo Vermelho Distrófico, horizonte A moderado ou proeminente, de textura muito argilosa ou argilosa, relevo plano e suave ondulado, LVd2 (87,63\%); Latossolo Vermelho Distrófico, horizonte A moderado ou proeminente, de textura argilosa, relevo plano e suave ondulado, LVd3 (6,92\%); Nitossolo Vermelho Eutrófico, horizonte A moderado ou chernozêmico, de textura argilosa, relevo suave ondulado e ondulado, $\mathrm{NVe} 2(2,13 \%)$; Latossolo Vermelho Áplico, horizonte A moderado, de textura média, relevo plano e suave ondulado, LVa1 (2,03\%); Latossolo Vermelho Distrófico, horizonte A moderado ou proeminente, textura muito argilosa ou argilosa, relevo plano e suave ondulado, LVd8 (0,87\%); Neossolo Litólico Distrófico, horizonte A moderado, textura média cascalhenta fase pedregosa, relevo ondulado e forte ondulado,

$\begin{array}{lllll}\text { Caminhos de Geografia } & \text { Uberlândia-MG } & \text { v. 21, n. } 74 & \text { Abr/2020 } & \text { p. 01-20 }\end{array}$


RLd7 (0,34\%); e Latossolo Vermelho Distrófico, horizonte A moderado, de textura muito argilosa, relevo plano e suave ondulado, LVd1 (0,08\%), observar Figura 2 B (SIEG, 2017).

Tratando-se da hipsometria, a bacia hidrográfica em questão apresenta altitude de 525 a $870 \mathrm{~m}$ (Figura 2 C).

Quanto a declividade, em \%, conforme a classificação da Embrapa (2013), são apresentadas as classes da bacia do ribeirão da Laje: $0-3 \%$, relevo plano $(34,19 \%$ da área total); $3-8 \%$, relevo suave ondulado $(54,71 \%$ da área total); $8-20 \%$, relevo ondulado (10,86\% da área total); e $20-45 \%$, relevo forte ondulado (0,24 da área total), ver Figura $2 \mathrm{D}$.

Apresenta clima enquadrado no tipo AW, caracterizado por climas úmidos tropicais (PEEL et al., 2007), com temperaturas amenas durante o inverno e calor no verão, com um período mais seco, que abrange parte do outono/inverno e da primavera, e um período chuvoso, em parte da primavera/verão/outono. A vegetação natural predominante é do bioma Cerrado, com remanescentes localizados, principalmente, entre os vales fluviais na forma de matas de galeria, associados à maior umidade do ar (PRADO et al., 2009), além de mata ciliar e fragmentos de vegetação nativas.

\section{PROCESSAMENTO DIGITAL DE IMAGENS (TERCEIRA ETAPA)}

O shp da delimitação da bacia do ribeirão da Laje subsidiou também a extração das imagens correspondentes à área de estudo a partir das imagens em escalas pequenas obtidas no banco de dados geográficos do USGS (2017).

As bandas (B) multiespectrais usadas do Satélite Lansat 5/Sensor TM foram: B3 (Vermelho), B4 (Infravermelho próximo) e B5 (Infravermelho médio); e imagem do Satélite Landsat 8/Sensor OLI foram: B4 (Vermelho), B5 (Infravermelho próximo) e B6 (natural com remoção atmosférica). A composição colorida RGB (red, green e blue) das bandas das imagens do primeiro satélite foi $R / 3$, $\mathrm{G} / 4$ e $\mathrm{B} / 5$, e da imagem do segundo satélite, $\mathrm{R} / 4, \mathrm{G} / 5$ e $\mathrm{B} / 6$. Foram usadas essas combinações de bandas por apresentarem maior aproximação das cores reais ou naturais.

As imagens foram analisadas e classificadas com o uso da ferramenta Interactive Supervised Classification, reconhecimento de áreas de treinamento no Google Earth Pro para as imagens de 2007 e 2017 e, ainda, reconhecimento de áreas de treinamento em campo para a imagem do último ano para validação da legenda e mapas preliminares.

Com uso de uma câmera digital, modelo Nikon D5100, foram obtidas fotografias em campo, sendo estas georreferenciadas com um GPS modelo Garmin GPSMAP 62sc para fazer as correções necessárias nos mapas de uso e cobertura da terra.

Em seguida, as diferentes categorias de uso e cobertura da terra (solo exposto, eucalipto, agricultura, pastagem, vegetação remanescente, área urbana, área industrial, construção rural e represa) na bacia hidrográfica foram reclassificadas, convertidas para polígono e, no intuito de melhorar a qualidade da classificação, realizadas correções manualmente, em sequência, quantificadas as categorias.

\section{VALIDAÇÃO DOS PRODUTOS DIGITAIS (QUARTA ETAPA)}

Foram obtidas amostras de validação ou amostras kappa, de forma manual e aleatória, a partir de imagens do satélite Landsat 5/sensor TM e do satélite Landsat 8/sensor OLI para avaliação da classificação das imagens de 1987 e 1997, uso de imagens desses sensores e série histórica de imagens do Google Earth Pro para avaliar a classificação das imagens dos anos de 2007 e 2018, e, ainda, levantamentos de campo para apoiar a validação da classificação da imagem referente ao último ano.

Em seguida, por meio do QGIS 2.16 e seu complemento Acuracy, foi realizado o cruzamento de cada classificação, referente a cada ano em questão, com respectivas amostras de validação (amostras kappa) para obtenção das matrizes de confusão. A partir destas matrizes foi realizado o cálculo do Índice Kappa, sendo este um teste estatístico usado para avaliar a qualidade da classificação de imagem, recomendado por Rosenfield e Fitzpatrick-Lins (1986) por utilizar todas as células da matriz de erro, e não apenas os elementos da diagonal descendente, ou seja, mede a probabilidade de um pixel ser corretamente classificado em relação à probabilidade da classificação incorreta. Conforme Simões (2001), o Índice Kappa é calculado através da Equação 1 (E1):

$\begin{array}{llllll}\text { Caminhos de Geografia } & \text { Uberlândia-MG } & \text { v. 21, n. } 74 & \text { Abr/2020 } & \text { p. 01-20 } & \text { Página } 6\end{array}$


$\mathrm{K}=\mathrm{P} 0-\mathrm{Pe} / 1-\mathrm{Pe}$

Na qual: P0 representa a exatidão geral da classificação (soma da coluna diagonal da matriz dividida pelo número total de "pixels" amostrados); $\mathrm{Pe}$, a $\Sigma \mathrm{p}_{i_{+}} \mathrm{p}_{+\mathrm{i}}$, sendo $\mathrm{p}_{i_{+}}$e $\mathrm{p}_{+\mathrm{i}}$ as proporções marginais da linha i e da coluna i, respectivamente.

Podendo este índice ser estimado de forma mais simples através da Equação 2 (E2):

$\mathrm{K}=\left(\mathrm{n} * \sum_{\mathrm{i}=1}^{\mathrm{e}} \mathrm{X}_{\mathrm{i} i}-\sum_{\mathrm{j}=1}^{\mathrm{e}} \mathrm{X}_{1+*} \mathrm{X}_{+1}\right) /\left(\mathrm{n}^{2}-\sum_{\mathrm{j}=1}^{\mathrm{e}} \mathrm{X}_{1+*} \mathrm{X}_{+1}\right)$

Na qual: K é uma estimativa do coeficiente Kappa; n é o número total de amostras; c é o número total de classes; $x_{i i}$ é o valor na linha i e coluna i, ou seja, o valor da diagonal da matriz de confusão, de forma descendente; $x_{i+}$ é a soma da linha $\mathrm{i}$; e $\mathrm{x}_{+\mathrm{i}}$ é a soma da coluna i da matriz.

A qualidade da classificação foi avaliada segundo os parâmetros apresentados no Quadro 1.

Quadro 1 - Qualidade da classificação segundo intervalos do Índice Kappa.

\begin{tabular}{|c|c|}
\hline Valor Kappa & Qualidade da classificação \\
\hline$<0,00$ & Péssima \\
\hline $0,00-0,20$ & Ruim \\
\hline $0,20-0,40$ & Razoável \\
\hline $0,40-0,60$ & Boa \\
\hline $0,60-0,80$ & Muito Boa \\
\hline $0,80-1,00$ & Excelente \\
\hline
\end{tabular}

Fonte - Landis e Koch (1977)

Conforme Quadro 1, a qualidade de uma classificação de imagem pode variar de péssima $(<0,00)$ à excelente $(0,80-1,00)$.

\section{ANÁLISE DE RESULTADOS (QUINTA ETAPA)}

No intuito de melhor apresentar os resultados das mudanças do uso e cobertura da terra na bacia do ribeirão da Laje, foi utilizada a técnica da matriz de transição (Quadro 2). Essa matriz analisa o quantitativo de áreas que se mantem ou persiste entre dois momentos distintos e as alterações, sendo os valores relacionados às classes no momento 1 apresentados nas linhas, às classes no momento 2, nas colunas, e às persistências, na diagonal da matriz, de forma descendente, possibilitando quantificar os ganhos e as perdas de cada categoria. Através da soma de suas classes em cada linha com a subtração de sua persistência, é obtida a perda; por meio da soma das classes em cada coluna com a subtração de sua persistência, é obtido o ganho (PONTIUS JR. et al., 2004).

Quadro 2 - Matriz geral de tabulação cruzada para a comparação de dois mapas em dois momentos distintos.

\begin{tabular}{|c|c|c|c|c|c|c|}
\hline \multirow[b]{2}{*}{ Classe no momento 1} & \multicolumn{4}{|c|}{ Classe no momento 2} & \multirow{2}{*}{$\begin{array}{c}\text { Total no } \\
\text { momento } 1\end{array}$} & \multirow[b]{2}{*}{ Perda } \\
\hline & $\begin{array}{c}\text { Classe } 1 \\
\text { (j) }\end{array}$ & $\begin{array}{c}\text { Classe } 2 \\
(\mathrm{j}+1)\end{array}$ & $\begin{array}{c}\text { Classe } 3 \\
(j+2)\end{array}$ & $\begin{array}{c}\text { Classe } 4 \\
(\mathrm{j}+3)\end{array}$ & & \\
\hline $\begin{array}{l}\text { Classe } 1 \\
\text { (i) }\end{array}$ & $\mathrm{C}_{11}$ & $\mathrm{C}_{12}$ & $\mathrm{C}_{13}$ & $\mathrm{C}_{14}$ & $\sum_{\mathrm{j}=1}^{\mathrm{n}} \mathrm{C}_{1+}$ & $\sum_{\bar{i}=1}^{n} C_{1+}-C_{11}$ \\
\hline $\begin{array}{c}\text { Classe } 2 \\
(\mathrm{i}+1)\end{array}$ & $\mathrm{C}_{21}$ & $\mathrm{C}_{22}$ & $\mathrm{C}_{23}$ & $\mathrm{C}_{24}$ & $\sum_{\mathrm{i}=1}^{\mathrm{n}} \mathrm{C}_{2+}$ & $\sum_{\mathrm{i}=1}^{\mathrm{n}} \mathrm{C}_{2+}-\mathrm{C}_{22}$ \\
\hline $\begin{array}{c}\text { Classe } 3 \\
(\mathrm{i}+2)\end{array}$ & $\mathrm{C}_{31}$ & $\mathrm{C}_{32}$ & $\mathrm{C}_{33}$ & $\mathrm{C}_{34}$ & $\sum_{\mathrm{j}=1}^{\mathrm{n}} \mathrm{C}_{3+}$ & $\sum_{\mathrm{i}=1}^{\mathrm{n}} \mathrm{C}_{3+}-\mathrm{C}_{33}$ \\
\hline $\begin{array}{c}\text { Classe } 4 \\
(\mathrm{i}+3)\end{array}$ & $\mathrm{C}_{41}$ & $\mathrm{C}_{42}$ & $\mathrm{C}_{43}$ & $\mathrm{C}_{44}$ & $\sum_{i=1}^{n} C_{3+}$ & $\sum_{\mathrm{j}=1}^{\mathrm{n}} \mathrm{C}_{4+}-\mathrm{C}_{44}$ \\
\hline $\begin{array}{c}\text { Total no } \\
\text { momento } 2\end{array}$ & $\sum_{\mathrm{i}=1}^{\mathrm{n}} \mathrm{C}_{+1}$ & $\sum_{\mathrm{i}=1}^{\mathrm{n}} \mathrm{C}_{+2}$ & $\sum_{\mathrm{i}=1}^{\mathrm{n}} \mathrm{C}_{+3}$ & $\sum_{\mathrm{i}=1}^{\mathrm{n}} \mathrm{C}_{+4}$ & $\sum_{\mathrm{i}=1}^{\mathrm{n}} \mathrm{C}_{\mathrm{ij}}=\mathrm{At}$ & \\
\hline Ganho & $\sum_{\mathrm{i}=1}^{\mathrm{n}} \mathrm{C}_{+1}-\mathrm{C}_{11}$ & $\sum_{\mathrm{i}=1}^{\mathrm{n}} \mathrm{C}_{+2}-\mathrm{C}_{22}$ & $\sum_{\mathrm{i}=1}^{\mathrm{n}} \mathrm{C}_{+3}-\mathrm{C}_{33}$ & $\sum_{\mathrm{i}=1}^{\mathrm{n}} \mathrm{C}_{44}-\mathrm{C}_{44}$ & & \\
\hline
\end{tabular}


Os dados do Quadro 2 são explicados em seguida. $C_{\mathrm{ij}}$ : é a mudança do uso e cobertura da terra, adimensional, da Classe i para a Classe j, sendo que as classes i, nas linhas, correspondem ao momento 1 , e as classes j, nas colunas, ao momento 2; $C_{j j}$ : é a persistência da classe; $\sum_{j=1}^{n} C_{1+}$ : na coluna Total momento 1 é o total da classe 1 no momento $1 ; \sum_{\mathrm{i}=1}^{\mathrm{n}} \mathrm{C}_{+1}$ : na linha Total momento 2 é o total da classe 1 no momento 2; Ganhos: total de classe na categoria j, $\mathrm{C}_{+1}$, pela diferença da persistência da classe $C_{\mathrm{jj}}$; Perda: representa o total das perdas relativas para cada classe de uso do solo i entre os momentos 1 e 2, é calculado para cada classe por meio da diferença entre o total da linha e a persistência para a classe correspondente (PONTIUS JR. et al., 2004).

Buscando melhor entender as mudanças no uso e cobertura da terra na bacia do ribeirão da Laje no decorrer dos anos, a partir da matriz de transição foram calculadas a percentagem de classe $(\% \mathrm{C})$, a troca $\left(S_{\mathrm{j}}\right)$ e a alteração total, conforme Equação 3 (E3), Equação 4 (E4) e Equação 5 (E5), respectivamente (PONTIUS JR. et al., 2004).

$\% \mathrm{C}_{\mathrm{i}, \mathrm{t}}=\left(\sum_{\mathrm{j}=1}^{\mathrm{n}} \mathrm{C}_{\mathrm{ij}}\right) / \mathrm{At}$

$\mathrm{Na}$ qual: \% $\mathrm{C}_{\mathrm{i}, \mathrm{t}}$ : percentagem de classe i no momento $\mathrm{t} ; \sum_{\mathrm{j}=1}^{\mathrm{n}} \mathrm{C}_{\mathrm{ij}}$ : somatório da classe específica; At: área total das classes em análise.

$S_{j}=2^{*} \min ^{*}\left(\left(\left(\sum_{j=1}^{n} C_{i j}-C_{j j}\right) / A t\right)^{*} 100,\left(\left(\sum_{i=1}^{n} C_{j j}-C_{j j}\right) / A t\right)^{*} 100\right)$, quando $i=j$

Na qual: $\left(\left(\sum_{\mathrm{j}=1}^{\mathrm{n}} \mathrm{C}_{\mathrm{ij}}-\mathrm{C}_{\mathrm{jj}}\right) / \mathrm{At}\right)^{*} 100$ : perdas da área total, em percentagem; $\left(\left(\sum_{\mathrm{i}=1}^{\mathrm{n}} \mathrm{C}_{\mathrm{ij}}-\mathrm{C}_{\mathrm{jj}}\right) / \mathrm{At}\right)^{*} 100:$ ganhos da área total, em percentagem.

Total mudança $=\left(\left(\left(\sum_{\mathrm{j}=1}^{\mathrm{n}} \mathrm{C}_{\mathrm{ij}}-\mathrm{C}_{\mathrm{jij}}\right) / A t\right)^{*} 100\right)+\left(\left(\left(\sum_{\mathrm{i}=1}^{\mathrm{n}} \mathrm{C}_{\mathrm{ij}}-\mathrm{C}_{\mathrm{j} j}\right) / A t\right)^{*} 100\right)$

\section{RESULTADOS E DISCUSSÃO}

As matrizes de confusão obtidas a partir da classificação das imagens e amostras de validação (amostras kappa) são apresentadas nas tabelas numeradas de 1 a 4.

Os resultados da análise espaço-temporal do uso e cobertura da terra na bacia do ribeirão da Laje são apresentados nas tabelas de número 5 a 16, com espacializações na Figura 3. Os resultados obtidos a partir das matrizes de confusão (Tabela 1; Tabela 2; Tabela 3; Tabela 4) e da E2 (Índice Kappa) para os anos 1987, 1997, 2007 e 2017 foram, na ordem em que aparecem, 0,98, 0,97, 0,98 e 0,94 . Conforme Landis e Koch (1977), esses índices indicam qualidade excelente para as quatro classificações (Quadro 1).

Tabela 1 - Matriz de confusão da classificação da imagem de 1987 da bacia do ribeirão da Laje (GO)

\begin{tabular}{ccccccccccc} 
& \multicolumn{1}{c}{ Amostra de validação (kappa). } \\
\cline { 2 - 11 } & A & B & C & D & E & F & G & H & I & Total \\
\hline A & 12 & 1 & 0 & 0 & 0 & 0 & 0 & 0 & 0 & 13 \\
B & 0 & 238 & 0 & 0 & 0 & 0 & 2 & 0 & 3 & 243 \\
C & 0 & 0 & 90 & 0 & 0 & 0 & 0 & 0 & 0 & 90 \\
D & 0 & 0 & 0 & 118 & 0 & 0 & 0 & 0 & 0 & 118 \\
E & 0 & 0 & 0 & 0 & 9 & 0 & 0 & 0 & 0 & 9 \\
F & - & - & - & - & - & - & - & - & - & - \\
G & 0 & 2 & 0 & 0 & 0 & 0 & 308 & 0 & 0 & 310 \\
H & 0 & 0 & 0 & 0 & 0 & 0 & 0 & 45 & 0 & 45 \\
I & 2 & 2 & 0 & 0 & 0 & 0 & 2 & 0 & 207 & 213 \\
Total & 14 & 243 & 90 & 118 & 9 & 0 & 312 & 45 & 210 & 1041 \\
\hline
\end{tabular}

Legenda - A: solo exposto; B: pastagem; C: área industrial; D: área urbana; E: construção rural; F: silvicultura; G: Cerrado/mata; H: represa; e l: área agrícola. 
Tabela 2 - Matriz de confusão da classificação da imagem de 1997 da bacia do ribeirão da Laje (GO) Amostra de validação (kappa).

\begin{tabular}{|c|c|c|c|c|c|c|c|c|c|c|}
\hline \multirow{2}{*}{ lasse } & \multicolumn{8}{|c|}{ Amostra de validação (kappa). } & \multirow[b]{2}{*}{ I } & \multirow[b]{2}{*}{ Total } \\
\hline & $A$ & B & $\mathrm{C}$ & $\mathrm{D}$ & $E$ & $\mathrm{~F}$ & $G$ & $\mathrm{H}$ & & \\
\hline A & 30 & 2 & 0 & 0 & 0 & 0 & 0 & 0 & 0 & 32 \\
\hline $\mathrm{B}$ & 0 & 221 & 0 & 0 & 0 & 0 & 1 & 0 & 3 & 225 \\
\hline C & 0 & 0 & 87 & 1 & 2 & 0 & 0 & 0 & 0 & 90 \\
\hline D & 0 & 0 & 1 & 102 & 1 & 0 & 0 & 0 & 0 & 104 \\
\hline $\mathrm{E}$ & 0 & 0 & 0 & 0 & 30 & 0 & 0 & 0 & 0 & 30 \\
\hline$\vec{F}$ & 0 & 1 & 0 & 0 & 0 & 35 & 1 & 0 & 2 & 39 \\
\hline$G$ & 0 & 2 & 0 & 1 & 0 & 0 & 303 & 0 & 0 & 306 \\
\hline $\mathrm{H}$ & 0 & 0 & 0 & 0 & 0 & 0 & 0 & 50 & 0 & 50 \\
\hline I & 2 & 3 & 0 & 0 & 0 & 0 & 0 & 0 & 245 & 250 \\
\hline Total & 32 & 229 & 88 & 104 & 33 & 35 & 305 & 50 & 250 & 1126 \\
\hline
\end{tabular}

Legenda - A: solo exposto; B: pastagem; C: área industrial; D: área urbana; E: construção rural; F: silvicultura; G: Cerrado/mata; H: represa; e I: área agrícola.

Tabela 3 - Matriz de confusão da classificação da imagem de 2007 da bacia do ribeirão da Laje (GO)

\begin{tabular}{|c|c|c|c|c|c|c|c|c|c|c|}
\hline \multirow{2}{*}{ Classe } & \multicolumn{10}{|c|}{ Amostra de validação (kappa). } \\
\hline & A & $\mathrm{B}$ & C & D & $\mathrm{E}$ & $\mathrm{F}$ & G & $\mathrm{H}$ & I & Total \\
\hline$A$ & 37 & 2 & 0 & 0 & 0 & 0 & 0 & 0 & 3 & 42 \\
\hline B & 1 & 233 & 0 & 0 & 0 & 0 & 0 & 0 & 1 & 235 \\
\hline C & 0 & 0 & 90 & 0 & 0 & 0 & 0 & 0 & 0 & 90 \\
\hline D & 0 & 0 & 0 & 101 & 0 & 0 & 0 & 0 & 0 & 101 \\
\hline$E$ & 0 & 0 & 0 & 0 & 32 & 0 & 0 & 0 & 0 & 32 \\
\hline $\mathrm{F}$ & 0 & 1 & 0 & 0 & 0 & 33 & 2 & 0 & 0 & 36 \\
\hline $\mathrm{G}$ & 0 & 2 & 0 & 0 & 0 & 0 & 298 & 0 & 0 & 300 \\
\hline $\mathrm{H}$ & 0 & 0 & 0 & 0 & 0 & 0 & 0 & 47 & 0 & 47 \\
\hline I & 2 & 1 & 0 & 0 & 0 & 0 & 0 & 0 & 233 & 236 \\
\hline Total & 40 & 239 & 90 & 101 & 32 & 33 & 300 & 47 & 237 & 1119 \\
\hline
\end{tabular}

Legenda - A: solo exposto; B: pastagem; C: área industrial; D: área urbana; E: construção rural; F: silvicultura; G: Cerrado/mata; H: represa; e I: área agrícola.

Tabela 4 - Matriz de confusão da classificação da imagem de 2017 da bacia do ribeirão da Laje (GO)

\begin{tabular}{ccccccccccc}
\hline & \multicolumn{1}{c}{ Amostra de validação (kappa). } \\
\cline { 2 - 10 } & A & B & C & D & E & F & G & H & I & Total \\
\hline A & 34 & 3 & 0 & 0 & 0 & 0 & 0 & 0 & 3 & 40 \\
B & 1 & 163 & 2 & 0 & 1 & 3 & 0 & 0 & 2 & 172 \\
C & 0 & 0 & 43 & 0 & 0 & 0 & 0 & 0 & 0 & 43 \\
D & 0 & 0 & 0 & 81 & 0 & 0 & 0 & 0 & 0 & 81 \\
E & 0 & 0 & 0 & 0 & 30 & 0 & 0 & 0 & 0 & 30 \\
F & 0 & 0 & 0 & 0 & 1 & 43 & 0 & 0 & 0 & 44 \\
G & 2 & 1 & 0 & 0 & 2 & 0 & 94 & 0 & 0 & 99 \\
H & 0 & 0 & 0 & 0 & 0 & 0 & 0 & 28 & 0 & 28 \\
I & 2 & 3 & 2 & 0 & 3 & 4 & 0 & 0 & 221 & 235 \\
Total & 39 & 170 & 47 & 81 & 37 & 50 & 94 & 28 & 226 & 772 \\
\hline B pastag
\end{tabular}

Legenda - A: solo exposto; B: pastagem; C: área industrial; D: área urbana; E: construção rural; F: silvicultura; G: Cerrado/mata; H: represa; e I: área agrícola.

Observa-se que em 1987 a área de estudo era ocupada, majoritariamente, por pastagem (56,68\%), seguida de agricultura $(21,55 \%)$, Cerrado/mata $(20,40 \%)$, área urbana $(0,76 \%)$, rodovia $(0,30 \%)$, área industrial $(0,18 \%)$, represa $(0,07 \%)$, solo exposto $(0,05 \%)$ e construção rural $(<0,01 \%)$ conforme Tabela 5, Tabela 6 e Figura 3 A.

No ano de 1997, a área destinada à pastagem diminuiu, mas ainda era predominante $(41,87 \%)$, seguida de agricultura $(37,01 \%)$, Cerrado/mata $(19,14 \%)$, área urbana $(1,12 \%)$, rodovias $(0,30 \%)$, área industrial $(0,20 \%)$, eucalipto $(0,14 \%)$, solo exposto $(0,13 \%)$, represa $(0,07 \%)$ e construção rural $(0,01 \%)$. Como nova categoria surge neste ano a cultura do eucalipto (Tabela 5 ; Tabela 6 ; Figura $3 \mathrm{~A}$; Figura $3 \mathrm{~B})$. 
Tabela 5 - Matriz de transição do uso e cobertura da terra, de 1987 para 1997, na bacia do ribeirão da Laje (GO).

\begin{tabular}{|c|c|c|c|c|c|c|c|c|c|c|c|}
\hline \multirow{2}{*}{$\begin{array}{l}\text { Categoria } \\
1987 \text { (ha) }\end{array}$} & \multicolumn{10}{|c|}{ Categoria 1997 (ha) } & \multirow{2}{*}{$\begin{array}{l}\text { Total } \\
1987\end{array}$} \\
\hline & $A$ & $B$ & $C$ & $D$ & $E$ & $\mathrm{~F}$ & $G$ & $\mathrm{H}$ & 1 & $J$ & \\
\hline $\bar{A}$ & 131,01 & 0,00 & 0,00 & 0,00 & 0,00 & 0,00 & 0,00 & 0,00 & 0,00 & 0,00 & 131,01 \\
\hline$B$ & 0,00 & 29,20 & 0,00 & 0,00 & 0,00 & 0,00 & 0,00 & 0,00 & 0,00 & 0,00 & 29,20 \\
\hline C & 0,00 & 0,00 & 22,89 & 0,00 & 0,00 & 0,00 & 0,00 & 0,00 & 0,00 & 0,00 & 22,89 \\
\hline D & 0,00 & 0,00 & 0,00 & 0,00 & 0,00 & 0,00 & 0,00 & 0,00 & 0,00 & 0,00 & 0,00 \\
\hline$E$ & 0,00 & 0,11 & 30,46 & 0,00 & 6956,37 & 2283,50 & 24,65 & 0,00 & 0,00 & 4,39 & 9299,48 \\
\hline $\mathrm{F}$ & 0,00 & 0,00 & 0,65 & 60,30 & 8752,82 & 15374,16 & 111,33 & 153,37 & 9,03 & 0,00 & 24461,66 \\
\hline G & 0,00 & 0,28 & 0,01 & 0,00 & 259,97 & 411,89 & 8124,33 & 6,65 & 0,00 & 0,60 & 8803,72 \\
\hline $\mathrm{H}$ & 0,00 & 0,00 & 0,00 & 0,00 & 2,40 & 0,54 & 0,00 & 324,62 & 0,00 & 0,00 & 327,56 \\
\hline I & 0,00 & 0,00 & 0,00 & 0,00 & 0,00 & 0,00 & 0,00 & 0,00 & 78,13 & 0,00 & 78,13 \\
\hline J & 0,00 & 0,00 & 0,00 & 0,00 & 0,00 & 0,00 & 0,00 & 0,00 & 0,00 & 1,34 & 1,34 \\
\hline $\begin{array}{l}\text { Total } \\
1997\end{array}$ & 131,01 & 29,59 & 54,01 & 60,30 & 159 & 18070,09 & 8260,31 & 484,64 & 87,17 & 6,33 & 43 \\
\hline
\end{tabular}

Legenda: A: rodovia; B: represa; C: solo exposto; D: eucalipto; E: agricultura: F: pastagem; G: Cerrado/mata; H: área urbana; I: área industrial; J: construção rural.

Tabela 6 - Área total e variação líquida de cada categoria do uso e cobertura da terra, de 1987 para 1997, na bacia do ribeirão da Laje (GO).

\begin{tabular}{ccccccc}
\hline Categoria & $\begin{array}{c}\text { Total } 1987 \\
\text { (ha) }\end{array}$ & \%C 1987 & $\begin{array}{c}\text { Total 1997 } \\
\text { (ha) }\end{array}$ & \%C 1997 & $\begin{array}{c}\text { Variação líquida } \\
\text { (ha) }\end{array}$ & $\begin{array}{c}\text { Variação líquida } \\
(\%)\end{array}$ \\
\hline A & 131,01 & 0,30 & 131,01 & 0,30 & 0,00 & 0,00 \\
B & 29,20 & 0,07 & 29,59 & 0,07 & 0,39 & $<0,01$ \\
C & 22,89 & 0,05 & 54,01 & 0,13 & 31,11 & 0,07 \\
D & 0,00 & 0,00 & 60,30 & 0,14 & 60,30 & 15,46 \\
E & 9299,48 & 21,55 & 15971,56 & 37,01 & 6672,08 & 14,81 \\
F & 24461,66 & 56,68 & 18070,09 & 41,87 & 6391,57 & 1,26 \\
G & 8803,72 & 20,40 & 8260,31 & 19,14 & 543,41 & 0,36 \\
H & 327,56 & 0,76 & 484,64 & 1,12 & 157,08 & 0,02 \\
I & 78,13 & 0,18 & 87,17 & 0,20 & 9,03 & 0,01 \\
J & 1,34 & $<0,01$ & 6,33 & 0,01 & 4,99 & 32,14 \\
\hline Total & 43155,00 & 100,00 & 43155,00 & 100,00 & 13869,97 & \\
\hline
\end{tabular}

Legenda - A: rodovia; B: represa; C: solo exposto; D: eucalipto; E: agricultura: F: pastagem; G: Cerrado/mata; H: área urbana; I: área industrial; J: construção rural.

Nota-se que de 1987 para 1997, as áreas persistes, ou seja, as áreas que não sofreram alteração, em relação à área total da bacia hidrográfica em questão, foram: 35,63\% (pastagem), 18,83\% (Cerrado/mata), 16,12\% (agricultura), 0,75\% (área urbana), 0,30\% (rodovia), área 0,18\% (industrial), $0,07 \%$ (represa) e $0,05 \%$ (solo exposto) (Tabela 5; Tabela 7; Figura 3 A; Figura 3 B).

Considerando, ainda, as alterações do uso e cobertura da terra de 1987 para 1997, observa-se que a maior perda ocorreu em áreas destinadas à pastagem $(21,06 \%)$, agricultura $(5,43 \%)$ e Cerrado/mata $(1,57 \%)$. Os maiores ganhos foram de áreas destinadas à agricultura $(20,89 \%)$, pastagem $(6,25 \%)$ e área urbana $(0,37 \%)$. Observa-se substituição expressiva de áreas de pastagem por área de agricultura, sendo que da área total destinada à pecuária bovina (24461,66 ha), 8752,82 ha passaram a integrar área de cultivo agrícola. Nota-se perda de 1,57\% e ganho de $0,32 \%$ de área de Cerrado/mata, sendo essas trocas ocorridas principalmente com áreas de pastagem e agricultura. As maiores mudanças ocorreram nas áreas de pastagem (11783,43 ha), agricultura (11358,30 ha), Cerrado/mata (815,37 ha) e área urbana (162,97 ha), conforme Tabela 5, Tabela 6, Tabela 7, Tabela 8, Figura 3 A e Figura 3 B.

Considerando o ano de 2007, a área de agricultura passou a ser predominante (49,19\%), a área de pastagem passou a corresponder a segunda maior (29,08\%), seguida de Cerrado/mata (18,77\%), área urbana $(2,09 \%)$, rodovia $(0,30 \%)$, área industrial $(0,27 \%)$, represa $(0,17 \%)$, solo exposto $(0,07 \%)$, construção rural $(0,06 \%)$ e eucalipto $(0,01 \%)$. Observa-se redução da área de Cerrado/mata e aumento das demais categorias, exceto de áreas de rodovias, em relação aos anos anteriores (Tabela 9; Tabela 10; Figura $3 \mathrm{C}$ ). 
Tabela 7 - Persistência, perdas e ganhos por cada categoria do uso e cobertura da terra, de 1987 para 1997, na bacia do ribeirão da Laje (GO).

\begin{tabular}{ccccccc}
\hline \multirow{2}{*}{ Categoria } & \multicolumn{5}{c}{ Em ha } & \multicolumn{5}{c}{ Em \% } \\
\cline { 2 - 7 } Persistência & Perda & Ganho & Persistência & Perda & Ganho \\
\hline A & 131,01 & 0,00 & 0,00 & 0,30 & 0,00 & 0,00 \\
B & 29,20 & 0,00 & 0,39 & 0,07 & 0,00 & $<0,01$ \\
C & 22,89 & 0,00 & 31,11 & 0,05 & 0,00 & 0,07 \\
D & 0,00 & 0,00 & 60,30 & 0,00 & 0,00 & 0,14 \\
E & 6956,37 & 2343,11 & 9015,19 & 16,12 & 5,43 & 20,89 \\
F & 15374,16 & 9087,50 & 2695,93 & 35,63 & 21,06 & 6,25 \\
G & 8124,33 & 679,39 & 135,98 & 18,83 & 1,57 & 0,32 \\
H & 324,62 & 2,94 & 160,02 & 0,75 & 0,01 & 0,37 \\
I & 78,13 & 0,00 & 9,03 & 0,18 & 0,00 & 0,02 \\
J & 1,34 & 0,00 & 4,99 & $<0,01$ & 0,00 & 0,01 \\
\hline Total & 31042,05 & 12112,95 & 12112,95 & 71,93 & 28,07 & 28,07 \\
\hline \multicolumn{7}{c}{ Área total $=43155,00$ ha } \\
\hline
\end{tabular}

Legenda - A: rodovia; B: represa; C: solo exposto; D: eucalipto; E: agricultura: F: pastagem; G: Cerrado/mata; H: área urbana; I: área industrial; J: construção rural.

Tabela 8 - Perdas, ganhos, troca, valor absoluto da variação líquida e total de mudanças de cada categoria do uso e cobertura da terra, de 1987 para 1997, na bacia do ribeirão da Laje.

\begin{tabular}{cccccc} 
Categoria (ha) & Perda & Ganho & $\begin{array}{c}\text { Variação } \\
\text { líquida }\end{array}$ & Troca & $\begin{array}{c}\text { Total de } \\
\text { mudança }\end{array}$ \\
\hline A & 0,00 & 0,00 & 0,00 & 0,00 & 0,00 \\
B & 0,00 & 0,39 & 0,39 & 0,00 & 0,39 \\
C & 0,00 & 31,11 & 31,11 & 0,00 & 31,11 \\
D & 0,00 & 60,30 & 60,30 & 0,00 & 60,30 \\
E & 2343,11 & 9015,19 & 6672,08 & 4686,22 & 11358,30 \\
F & 9087,50 & 2695,93 & 6391,57 & 5391,87 & 11783,43 \\
G & 679,39 & 135,98 & 543,41 & 271,96 & 815,37 \\
H & 2,94 & 160,02 & 157,08 & 5,89 & 162,97 \\
I & 0,00 & 9,03 & 9,03 & 0,00 & 9,03 \\
J & 0,00 & 4,99 & 4,99 & 0,00 & 4,99 \\
\hline Total & 12112,95 & 12112,95 & 13869,97 & 10355,93 & 24225,90
\end{tabular}

Legenda - A: rodovia; B: represa; C: solo exposto; D: eucalipto; E: agricultura: F: pastagem; G: Cerrado/mata; H: área urbana; I: área industrial; J: construção rural.

Em relação ao ano de 1997 e 2007, a maior persistência é de área de agricultura (33,80\%), seguida de pastagem $(25,62 \%)$, Cerrado/mata $(18,69 \%)$ e área urbana $(1,11 \%)$. A maior perda foi observada na área de pastagem (16,25\%), principalmente para integrar novas áreas de produção de grãos e cana-de-açúcar. A área de pastagem apresentou maior variação líquida $(95520,27 \mathrm{ha})$, seguida, principalmente, de área de agricultura (5254,74 ha), área urbana (415,18 ha) e área de Cerrado/mata $(415,18 \mathrm{ha})$. As maiores trocas foram observadas nas áreas de pastagem (2983,64 ha), agricultura ( $2770,82 \mathrm{ha})$ e Cerrado/mata $(69,13 \mathrm{ha})$, e os maiores totais de mudanças, nas áreas de pastagem (8503,91 ha), agricultura (8025,56 ha), área urbana (426,34 ha), Cerrado/mata (228,68 ha), ver Tabela 11, Tabela 12, Figura 3 B e Figura 3 C.

Tabela 9 - Matriz de transição do uso e cobertura da terra, de 1997 para 2007, na bacia do ribeirão da Laje (GO).

\begin{tabular}{|c|c|c|c|c|c|c|c|c|c|c|c|}
\hline \multirow{2}{*}{$\begin{array}{l}\text { Categoria } \\
1997 \text { (ha) }\end{array}$} & \multicolumn{10}{|c|}{ Categoria 2007 (ha). } & \multirow{2}{*}{$\begin{array}{l}\text { Total } \\
1997\end{array}$} \\
\hline & $A$ & $\mathrm{~B}$ & C & $\mathrm{D}$ & $E$ & $\mathrm{~F}$ & $G$ & $\mathrm{H}$ & I & $\mathrm{J}$ & \\
\hline$A$ & 131,01 & 0,00 & 0,00 & 0,00 & 0,00 & 0,00 & 0,00 & 0,00 & 0,00 & 0,00 & 131,01 \\
\hline B & 0,00 & 29,47 & 0,00 & 0,00 & 0,00 & 0,05 & 0,06 & 0,00 & 0,00 & 0,00 & 29,59 \\
\hline C & 0,00 & 0,00 & 20,00 & 0,00 & 19,00 & 0,01 & 1,00 & 4,00 & 10,00 & 0,00 & 54,01 \\
\hline D & 0,00 & 0,00 & 0,00 & 2,46 & 9,50 & 48,33 & 0,00 & 0,00 & 0,01 & 0,00 & 60,30 \\
\hline$E$ & 0,00 & 13,92 & 10,49 & 0,00 & 14586,15 & 1328,26 & 6,92 & 3,88 & 10,80 & 11,15 & 15971,56 \\
\hline $\mathrm{F}$ & 0,00 & 0,00 & 0,40 & 0,00 & 6559,82 & 11058,00 & 25,34 & 387,73 & 30,06 & 8,74 & 18070,09 \\
\hline G & 0,00 & 27,85 & 0,00 & 0,00 & 49,93 & 90,56 & 8066,20 & 25,15 & 0,00 & 0,62 & 8260,31 \\
\hline $\mathrm{H}$ & 0,00 & 0,00 & 0,00 & 0,00 & 0,00 & 4,34 & 1,24 & 479,06 & 0,00 & 0,00 & 484,64 \\
\hline I & 0,00 & 0,00 & 0,00 & 0,00 & 1,91 & 20,26 & 0,00 & 0,00 & 65,00 & 0,00 & 87,17 \\
\hline $\mathrm{J}$ & 0,00 & 0,00 & 0,00 & 0,00 & 0,00 & 0,00 & 0,00 & 0,00 & 0,00 & 6,33 & 6,33 \\
\hline $\begin{array}{l}\text { Total } \\
2007\end{array}$ & 131,01 & 71,24 & 30,89 & 2,46 & 21226,30 & 12549,82 & 8100,77 & 899,82 & 115,87 & 26,84 & 43155,00 \\
\hline
\end{tabular}

Legenda - A: rodovia; B: represa; C: solo exposto; D: eucalipto; E: agricultura: F: pastagem; G: Cerrado/mata; H: área urbana; I: área industrial; J: construção rural.

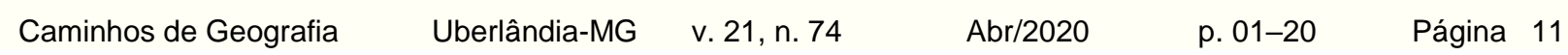


Tabela 10 - Área total e variação líquida de cada categoria do uso e cobertura da terra, de 1997 para 2007, na bacia do ribeirão da Laje (GO).

\begin{tabular}{ccccccc}
\hline Categoria & $\begin{array}{c}\text { Total } 1997 \\
\text { (ha) }\end{array}$ & $\%$ C 1997 & $\begin{array}{c}\text { Total } 2007 \\
\text { (ha) }\end{array}$ & $\%$ C 2007 & $\begin{array}{c}\text { Variação líquida } \\
\text { (ha) }\end{array}$ & $\begin{array}{c}\text { Variação líquida } \\
(\%)\end{array}$ \\
\hline A & 131,01 & 0,30 & 131,01 & 0,30 & 0,00 & 0,00 \\
B & 29,59 & 0,07 & 71,24 & 0,17 & 41,65 & 0,10 \\
C & 54,01 & 0,13 & 30,89 & 0,07 & 23,12 & 0,05 \\
D & 60,30 & 0,14 & 2,46 & 0,01 & 57,84 & 0,13 \\
E & 15971,56 & 37,01 & 21226,30 & 49,19 & 5254,74 & 12,18 \\
F & 18070,09 & 41,87 & 12549,82 & 29,08 & 5520,27 & 12,79 \\
G & 8260,31 & 19,14 & 8100,77 & 18,77 & 159,55 & 0,37 \\
H & 484,64 & 1,12 & 899,82 & 2,09 & 415,18 & 0,96 \\
I & 87,17 & 0,20 & 115,87 & 0,27 & 28,70 & 0,07 \\
J & 6,33 & 0,01 & 26,84 & 0,06 & 20,51 & 0,05 \\
\hline Total & 43155,00 & 100,00 & 43155,00 & 100,00 & 11521,56 & 26,70
\end{tabular}

Legenda - A: rodovia; B: represa; C: solo exposto; D: eucalipto; E: agricultura: F: pastagem; G: Cerrado/mata; H: área urbana; I: área industrial; J: construção rural.

Tabela 11 - Persistência, perdas e ganhos por cada categoria do uso e cobertura da terra, de 1997 para 2007, na bacia do ribeirão Laje (GO).

\begin{tabular}{ccccccc}
\hline \multirow{2}{*}{ Categoria } & \multicolumn{3}{c}{ Em ha } & \multicolumn{3}{c}{ Em \% } \\
\cline { 2 - 7 } & Persistência & Perda & Ganho & Persistência & Perda & Ganho \\
\hline A & 131,01 & 0,00 & 0,00 & 0,30 & 0,00 & 0,00 \\
B & 29,47 & 0,12 & 41,77 & 0,07 & 0,00 & 0,10 \\
C & 20,00 & 34,01 & 10,89 & 0,05 & 0,08 & 0,03 \\
D & 2,46 & 57,84 & $<0,01$ & 0,01 & 0,13 & $<0,01$ \\
E & 14586,15 & 1385,41 & 6640,15 & 33,80 & 3,21 & 15,39 \\
F & 11058,00 & 7012,09 & 1491,82 & 25,62 & 16,25 & 3,46 \\
G & 8066,20 & 194,11 & 34,57 & 18,69 & 0,45 & 0,08 \\
H & 479,06 & 5,58 & 420,76 & 1,11 & 0,01 & 0,98 \\
I & 65,00 & 22,17 & 50,87 & 0,15 & 0,05 & 0,12 \\
J & 6,33 & 0,00 & 20,51 & 0,01 & 0,00 & 0,05 \\
\hline Total & 34443,67 & 8711,33 & 8711,33 & 79,81 & 20,19 & 20,19 \\
\hline \multicolumn{7}{c}{ Área total = 43155,00 ha }
\end{tabular}

Legenda - A: rodovia; B: represa; C: solo exposto; D: eucalipto; E: agricultura: F: pastagem; G: Cerrado/mata; H: área urbana; I: área industrial; J: construção rural.

Considerando o ano de 2017, observa-se que a área destinada à agricultura se destaca entre as outras com $61,31 \%$ da área total da bacia hidrográfica. A área de Cerrado/mata passou a ser a segunda maior $(18,64 \%)$, entretanto com percentual menor em relação aos anos anteriores. Em seguida, destaca-se a área de pastagem $(15,67 \%)$, urbana $(2,67 \%)$, seguida, com menor representatividade, de área industrial $(0,86 \%)$, rodovia $(0,30 \%)$, construção rural $(0,25 \%)$, represa $(0,16 \%)$, solo exposto $(0,08 \%)$ e eucalipto $(0,05 \%)$, ver Tabela 13 , Tabela 14 e Figura 3 D.

Tabela 12 - Perdas, ganhos, troca, valor absoluto da variação líquida e total de mudanças de cada categoria do uso e cobertura da terra, de 1997 para 2007, na bacia do ribeirão da Laje (GO).

\begin{tabular}{cccccc}
\hline Categoria (ha) & Perda & Ganho & $\begin{array}{c}\text { Variação } \\
\text { líquida }\end{array}$ & Troca & $\begin{array}{c}\text { Total de } \\
\text { mudança }\end{array}$ \\
\hline A & 0,00 & 0,00 & 0,00 & 0,00 & 0,00 \\
B & 0,12 & 41,77 & 41,65 & 0,23 & 41,89 \\
C & 34,01 & 10,89 & 23,12 & 21,78 & 44,90 \\
D & 57,84 & $<0,01$ & 57,84 & $<0,01$ & 57,85 \\
E & 1385,41 & 6640,15 & 5254,74 & 2770,82 & 8025,56 \\
F & 7012,09 & 1491,82 & 5520,27 & 2983,64 & 8503,91 \\
G & 194,11 & 34,57 & 159,55 & 69,13 & 228,68 \\
H & 5,58 & 420,76 & 415,18 & 11,16 & 426,34 \\
I & 22,17 & 50,87 & 28,70 & 44,33 & 73,03 \\
J & 0,00 & 20,51 & 20,51 & 0,00 & 20,51 \\
\hline Total & 8711,33 & 8711,33 & 11521,56 & 5901,11 & 17422,66 \\
\hline
\end{tabular}

Legenda - A: rodovia; B: represa; C: solo exposto; D: eucalipto; E: agricultura: F: pastagem; G: Cerrado/mata; H: área urbana; I: área industrial; J: construção rural. 
Tabela 13 - Matriz de transição do uso e cobertura da terra, de 2007 para 2017, na bacia do ribeirão da Laje (GO).

\begin{tabular}{|c|c|c|c|c|c|c|c|c|c|c|c|}
\hline \multirow{2}{*}{$\begin{array}{l}\text { Categoria } \\
2007 \text { (ha) }\end{array}$} & \multicolumn{10}{|c|}{ Categoria 2017 (ha) } & \multirow{2}{*}{$\begin{array}{l}\text { Total } \\
2007\end{array}$} \\
\hline & A & $\mathrm{B}$ & $\mathrm{C}$ & $\mathrm{D}$ & $E$ & $\mathrm{~F}$ & $\mathrm{G}$ & $\mathrm{H}$ & $\mathrm{I}$ & $\mathrm{J}$ & \\
\hline$A$ & 131,01 & 0,00 & 0,00 & 0,00 & 0,00 & 0,00 & 0,00 & 0,00 & 0,00 & 0,00 & 131,01 \\
\hline B & 0,00 & 67,92 & 0,00 & 0,00 & 0,02 & 0,00 & 3,24 & 0,06 & 0,00 & 0,00 & 71,24 \\
\hline C & 0,00 & 0,00 & 15,88 & 0,00 & 1,56 & 0,32 & 0,00 & 0,00 & 13,13 & 0,00 & 30,89 \\
\hline D & 0,00 & 0,00 & 0,00 & 2,46 & 0,00 & 0,00 & 0,00 & 0,00 & 0,00 & 0,00 & 2,46 \\
\hline $\mathrm{E}$ & 0,00 & 0,04 & 11,20 & 11,01 & 20851,00 & 120,20 & 33,11 & 55,19 & 99,15 & 45,40 & 21226,30 \\
\hline $\mathrm{F}$ & 0,00 & 0,03 & 9,51 & 7,86 & 5484,22 & 6599,87 & 91,20 & 185,83 & 135,11 & 36,20 & 12549,82 \\
\hline G & 0,00 & 1,28 & 0,00 & 0,01 & 119,79 & 43,33 & 7915,86 & 13,07 & 7,43 & 0,00 & 8100,77 \\
\hline $\mathrm{H}$ & 0,00 & 0,00 & 0,00 & 0,00 & 0,00 & 0,00 & 0,05 & 899,77 & 0,00 & 0,00 & 899,82 \\
\hline I & 0,00 & 0,00 & 0,00 & 0,20 & 0,00 & 0,00 & 0,00 & 0,00 & 115,67 & 0,00 & 115,87 \\
\hline J & 0,00 & 0,00 & 0,00 & 0,00 & 0,00 & 0,00 & 0,10 & 0,00 & 0,00 & 26,74 & 26,84 \\
\hline $\begin{array}{l}\text { Total } \\
2017\end{array}$ & 131,01 & 69,27 & 36,59 & 21,53 & 26456,59 & 6763,72 & 8043,56 & 1153,92 & 370,49 & 108,34 & 43155,02 \\
\hline
\end{tabular}

Tabela 14 - Área total e variação líquida de cada categoria do uso e cobertura da terra, de 2007 para

\begin{tabular}{ccccccc}
\multicolumn{7}{c}{ 2017, na bacia do ribeirão da Laje (GO). } \\
\hline Categoria & $\begin{array}{c}\text { Total } 2007 \\
\text { (ha) }\end{array}$ & $\begin{array}{c}\text { \% } 2007 \\
\text { Total } 2017 \\
\text { (ha) }\end{array}$ & $\begin{array}{c}\text { \%C } 2017 \\
\text { Variação líquida } \\
\text { (ha) }\end{array}$ & $\begin{array}{c}\text { Variação líquida } \\
\text { (\%) }\end{array}$ \\
\hline A & 131,01 & 0,30 & 131,01 & 0,30 & 0,00 & 0,00 \\
B & 71,24 & 0,17 & 69,27 & 0,16 & 1,97 & $<0,01$ \\
C & 30,89 & 0,07 & 36,59 & 0,08 & 5,70 & 0,01 \\
D & 2,46 & 0,01 & 21,53 & 0,05 & 19,08 & 0,04 \\
E & 21226,30 & 49,19 & 26456,59 & 61,31 & 5230,29 & 12,12 \\
F & 12549,82 & 29,08 & 6763,72 & 15,67 & 5786,10 & 13,41 \\
G & 8100,77 & 18,77 & 8043,56 & 18,64 & 57,21 & 0,13 \\
H & 899,82 & 2,09 & 1153,92 & 2,67 & 254,10 & 0,59 \\
I & 115,87 & 0,27 & 370,49 & 0,86 & 254,62 & 0,59 \\
J & 26,84 & 0,06 & 108,34 & 0,25 & 81,50 & 0,19 \\
\hline Total & 43155,02 & 100,00 & 43155,02 & 100,00 & 11690,56 & 27,09
\end{tabular}

Legenda - A: rodovia; B: represa; C: solo exposto; D: eucalipto; E: agricultura: F: pastagem; G: Cerrado/mata; H: área urbana; I: área industrial; J: construção rural.

Ao analisar as mudanças do uso e cobertura da terra considerando os anos de 2007 e 2017, observa-se maior persistência da área de agricultura (48,32\%), seguida, principalmente, de área de Cerrado/mata $(18,34 \%)$, pastagem $(15,29 \%)$ e área urbanizada $(2,08 \%)$. A maior variação líquida foi observada na área de pastagem (13,41\%), seguida, principalmente, de área agrícola $(12,12 \%)$, industrial $(0,59 \%)$, urbana $(0,59 \%)$, construção rural $(0,19 \%)$ e Cerrado/mata $(0,13 \%)$. A maior perda foi de área de pastagem (13,79\%), principalmente para novas áreas de agricultura. O maior ganho foi observado na área de agricultura (12,99\%), seguida de área urbana $(0,59 \%)$ e industrial $(0,59 \%)$ (Tabela 13, Tabela 14, Tabela 15, Figura $3 \mathrm{C}$ e Figura $3 \mathrm{D}$ ).

Foram observadas maiores trocas, de 2007 para 2017, nas áreas de agricultura (750,61 ha), pastagem (327,69 ha), Cerrado/mata (255,40 ha) e solos exposto (30,03 ha). Quanto ao total de mudanças, as maiores foram na área de pastagem (6113,80 ha), agricultura (5980,89 ha), Cerrado/mata (312,60 ha), área industrial (255,02 ha) e urbana (254,20 ha).

O aumento das áreas de represa, ao longo dos anos, tem relação, principalmente, com barramentos de canais hídricos para atender a demanda de água na produção agrícola irrigada. Foram observados incrementos de áreas irrigadas por sistemas do tipo aspersão, sendo que não tinha instalação de pivô central em 1987, em 1997 havia um pivô central, e em 2007 e 2017 foram observados, respectivamente, 9 e 17 pivôs centrais de grande porte e vazão, com maior concentração na parte baixa da bacia hidrográfica, principalmente no município de Santo Antônio da Barra (GO), especialmente para irrigação de áreas de produção de soja e milho, além de ter sido observadas extensas áreas de cultivo de cana-de-açúcar irrigada por sistema autopropelido. O manejo da água para irrigação agrícola precisa ser conduzido de forma adequada, tendo em vista que, conforme Silva e Sousa (2012), a produção agrícola é a atividade econômica que mais consome

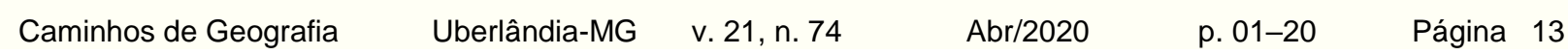


água e é a que mais causa impacto no solo e no bioma como um todo. Também é importante que os órgãos ambientais fiscalizem essas áreas e que a legislação de recursos hídricos seja cumprida, como, por exemplo, a outorga de direito de uso da água.

Figura 3 - Uso e cobertura da terra em 1987 (A), 1997 (B), 2007 (C) e 2017 (D), na bacia do ribeirão

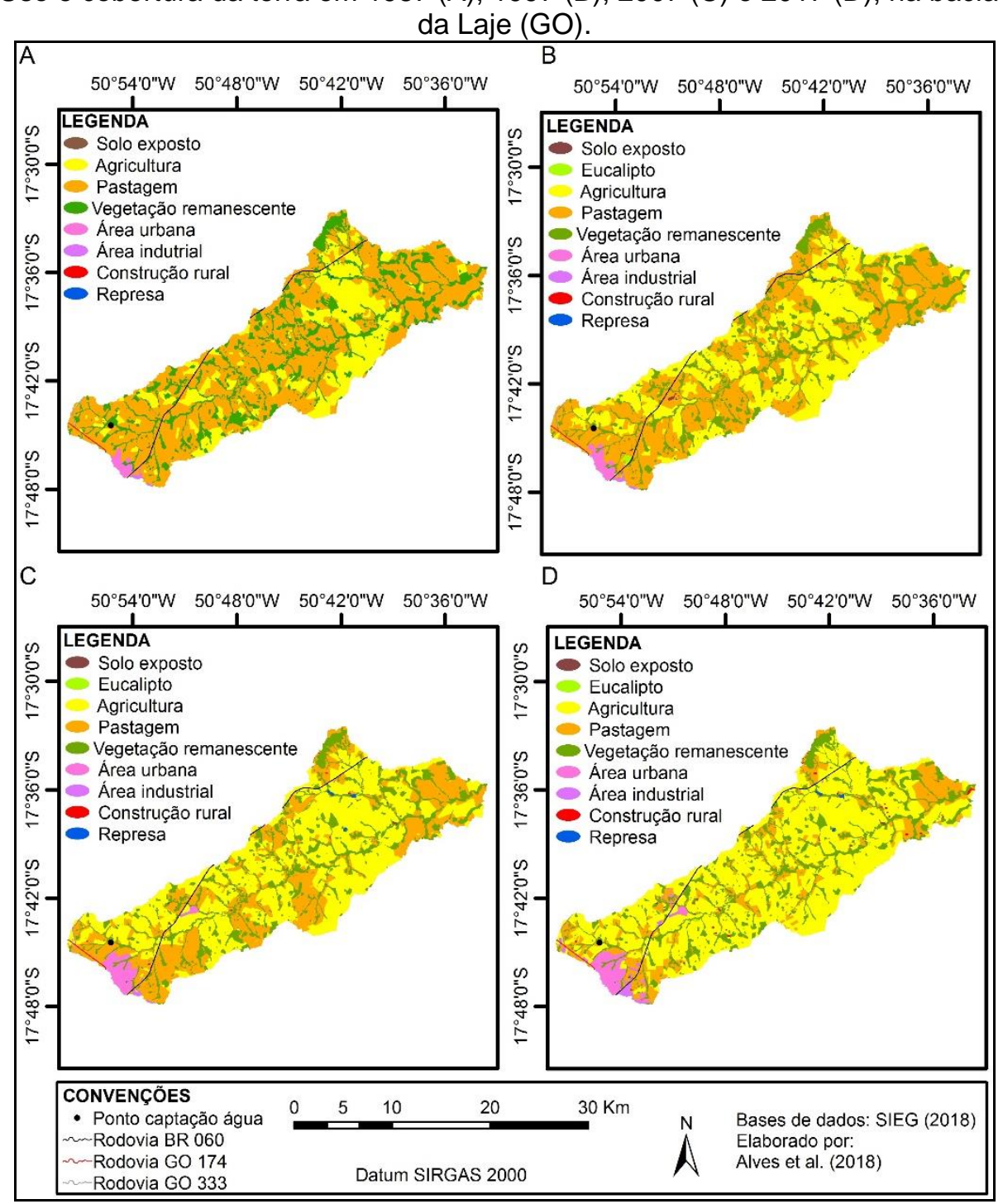

Fonte - Elaborado pelos autores a partir de imagens disponibilizadas pelo USGS (2017).

Tabela 15 - Persistência, perdas e ganhos por cada categoria do uso e cobertura da terra, de 2007 para 2017, na bacia do ribeirão da Laje (GO).

\begin{tabular}{ccccccc}
\hline \multirow{2}{*}{ Categoria } & \multicolumn{3}{c}{ Em ha } & \multicolumn{5}{c}{ Em \% } \\
\cline { 2 - 7 } & Persistência & Perda & Ganho & Persistência & Perda & Ganho \\
\hline A & 131,01 & 0,00 & 0,00 & 0,30 & 0,00 & 0,00 \\
B & 67,92 & 3,32 & 1,35 & 0,16 & 0,01 & $<0,01$ \\
C & 15,88 & 15,01 & 20,71 & 0,04 & 0,03 & 0,05 \\
D & 2,46 & 0,00 & 19,08 & 0,01 & 0,00 & 0,04 \\
E & 20851,00 & 375,30 & 5605,59 & 48,32 & 0,87 & 12,99 \\
F & 6599,87 & 5949,95 & 163,85 & 15,29 & 13,79 & 0,38 \\
G & 7915,86 & 184,91 & 127,70 & 18,34 & 0,43 & 0,30 \\
H & 899,77 & 0,05 & 254,15 & 2,08 & $<0,01$ & 0,59 \\
I & 115,67 & 0,20 & 254,82 & 0,27 & $<0,01$ & 0,59 \\
J & 26,74 & 0,10 & 81,60 & 0,06 & $<0,01$ & 0,19 \\
\hline Total & 36626,18 & 6528,84 & 6528,84 & 84,87 & 15,13 & 15,13 \\
\hline \multicolumn{7}{c}{ Área total = 43155 ha } \\
\hline
\end{tabular}

Legenda - A: rodovia; B: represa; C: solo exposto; D: eucalipto; E: agricultura: F: pastagem; G: Cerrado/mata; H: área urbana; I: área industrial; J: construção rural.

\begin{tabular}{|c|c|c|}
\hline Caminhos de Geografia & Uberlândia-MG & v. 21, n. 74 \\
\hline
\end{tabular}


O acréscimo de áreas de solo exposto é devido ao histórico de uso e manejo inadequados do solo na região, onde a vegetação natural foi sendo descaracterizada ao longo do tempo em decorrência das ações antrópicas para dar lugar às atividades agropecuárias em busca de ganhos em produtividade. Foram observadas áreas com erosão laminar e em sulco em diversos locais dentro da área de estudo, principalmente em áreas de pastagens degradadas (Figura 4; Figura 5), resultados da ausência ou ineficiência de planejamento e gestão condizentes com um meio ambiente ecologicamente equilibrado.

Tabela 16 - Perdas, ganhos, troca, valor absoluto da variação líquida e total de mudanças de cada categoria do uso e cobertura da terra, de 2007 para 2017, na bacia do ribeirão da Laje (GO)

\begin{tabular}{cccccc}
\hline Categoria (ha) & Perda & Ganho & $\begin{array}{c}\text { Variação } \\
\text { líquida }\end{array}$ & Troca & $\begin{array}{c}\text { Total de } \\
\text { mudança }\end{array}$ \\
\hline A & 0,00 & 0,00 & 0,00 & 0,00 & 0,00 \\
B & 3,32 & 1,35 & 1,97 & 2,70 & 4,67 \\
C & 15,01 & 20,71 & 5,70 & 30,03 & 35,72 \\
D & 0,00 & 19,08 & 19,08 & 0,00 & 19,08 \\
E & 375,30 & 5605,59 & 5230,29 & 750,61 & 5980,89 \\
F & 5949,95 & 163,85 & 5786,10 & 327,69 & 6113,80 \\
G & 184,91 & 127,70 & 57,21 & 255,40 & 312,60 \\
H & 0,05 & 254,15 & 254,10 & 0,10 & 254,20 \\
I & 0,20 & 254,82 & 254,62 & 0,40 & 255,02 \\
J & 0,10 & 81,60 & 81,50 & 0,20 & 81,70 \\
\hline Total & 6528,84 & 6528,84 & 11690,56 & 1367,13 & 13057,69 \\
\hline
\end{tabular}

Legenda - A: rodovia; B: represa; C: solo exposto; D: eucalipto; E: agricultura: F: pastagem; G: Cerrado/mata; H: área urbana; I: área industrial; J: construção rural.

Almeida et al. (2017), em outro estudo realizado em área de assentamentos rurais no norte de Minas Gerais, também destacam que as áreas com solo exposto (e/ou pastagem de baixa produtividade) em sua maioria foram provenientes de manejo inadequado do solo.

A implantação de áreas de eucalipto na bacia hidrográfica, concentradas no município de Rio Verde (GO), a partir de 1997, tem relação com a demanda energética da Cooperativa Agroindustrial dos Produtores Rurais do Sudoeste Goiano (COMIGO), fundada nesse município em 1975, uma das maiores cooperativas do Brasil, que usa esse vegetal como fonte de energia. Tem relação também com a BRF S. A., unidade de Rio Verde (GO), implantada em 1999, uma das maiores companhias de alimentos do mundo, que também utiliza a produção dessa silvicultura como fonte energética para seus processos produtivos, além de usar essas árvores como barreira de proteção de granjas destinadas à produção de aves e suínos.

Prado et al. (2009), no estudo do mapeamento e descrição do padrão de uso e cobertura da terra em municípios do sudoeste goiano, destacam que a produção de eucalipto está relacionada à criação de suínos e preparo de rejeitos destes animais com unidades da empresa BRF S. A., sendo essas arvores utilizadas como barreira à expansão do odor dos rejeitos dos suínos produzidos nas granjas. Martins et al. (2016), no estudo do uso e cobertura da terra de 1985 a 2015 no Sudoeste de Goiás e relação com o meio físico, relatam que a produção florestal, a partir de 2005, para atender a demanda energética de empresas da região, é um novo fator de transformação com papel fundamental sobre as relações de uso e cobertura da terra.

Figura 4 - Pastagens degradadas com presença de erosão na parte alta da microbacia do córrego Capivara, afluente do ribeirão da Laje (GO).

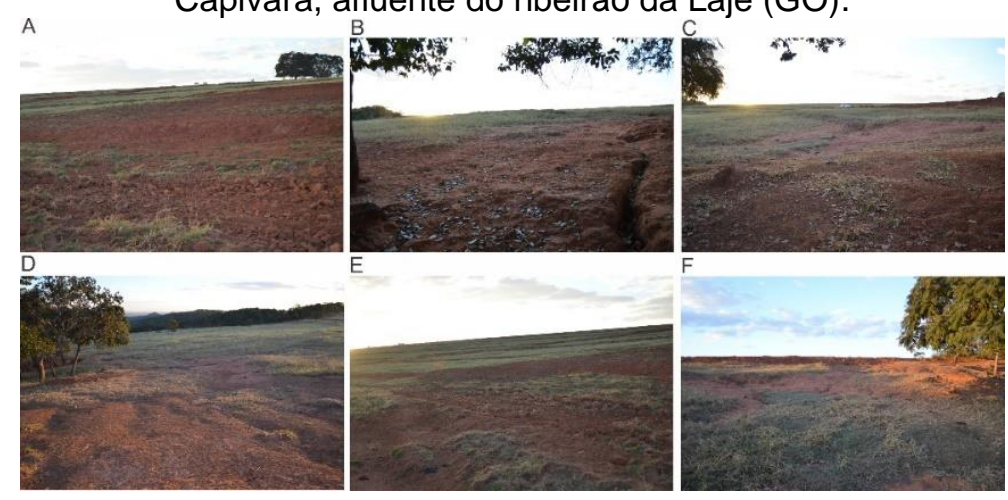


Figura 5 - Áreas degradadas com presença de erosão na bacia do ribeirão da Laje (GO).

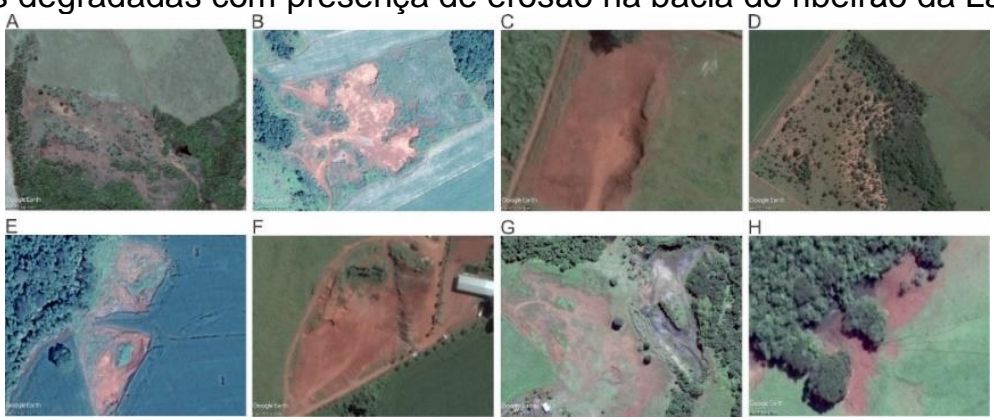

Fonte - Imagens do de 2017 do Google Earth Pro.

Observa-se que as áreas de agricultura (com destaque para produção de grãos e cana-de-açúcar) ocupam, principalmente, áreas embasadas por formações geológicas que originam solos com textura argilosa e médio argilosa/argilosa: Formação Serra Geral e Coberturas Detrito-Lateríticas Ferruginosas e Detríticas indiferenciadas (Figura 2 A; Figura 3).

No estudo realizado na microrregião Sudoeste de Goiás, Martins et al. (2016) também observaram que as áreas agrícolas ocupam, majoritariamente, áreas de chapadas, embasadas por formações que originam solos com textura argilosa e médio/argilosa, como, ressaltam os autores, as formações Cachoeirinha e Serra Geral e Coberturas Detrito-Lateríticas Ferruginosas e Detríticas indiferenciadas.

O aumento de área agrícola (principalmente produção de soja, milho e cana-de-açúcar, sendo esta cultura mais recente) na bacia hidrográfica em questão, seguido do decréscimo de área de pastagem e Cerrado/mata (sendo esta categoria presente majoritariamente em Área de Preservação Permanente (APP) nas margens de cursos hídricos e como fragmentos de vegetação ou Reserva Legal (RL)), de 1987 a 2017, pode ser explicado pelos aspectos físicos (predominância de Latossolos e baixas declividades), conforme apresentados na Figura 3, clima, vias de acesso (dentre as quais, as rodovias BR 060, GO 174 e GO 333), tecnologias e políticas públicas (como, por exemplo, PRODECER e POLOCENTRO) favoráveis a esse tipo de uso.

Martins et al. (2016) destacam que a predominância de baixas declividades, Latossolos, a pavimentação de rodovias, como a BR 060 (liga o Sudoeste de Goiás à capital do estado, Goiânia, e à capital federal, Brasília), tecnologias de produção e o investimento do Governo Federal em programas de ocupação e produção agropecuária nas regiões Norte e Centro-Oeste colocaram o Sudoeste de Goiás no mapa econômico do Brasil, sendo destaque na produção de grãos (principalmente soja e milho). Destacam, ainda, o cultivo de cana-de-açúcar para a produção de biocombustíveis, a partir de 2005, como um novo fator fundamental de transformação sobre as relações de uso e cobertura da terra (assim como os plantios florestais), competindo, em alguns municípios da região, com áreas de produção de grãos.

Dentre os fatores que contribuíram para efetivação da região enquanto produtora de grãos, Silva e Souza (2012) destacam: a proximidade com o mercado consumidor do Centro-Sul Brasileiro; a construção de rodovias; a construção de Brasília; as características geomorfológicas da região, terras planas que favoreceram a mecanização e a implantação de políticas públicas para fomentar a produção, como o POLOCENTRO, o Programa de Desenvolvimento Industrial (PRODUZIR) e o Fundo Constitucional do Centro-Oeste (FCO) do Ministério da Integração Nacional.

Os resultados obtidos para 2017 são proporcionalmente parecidos com os dados levantados por Prado et al. (2009) no mapeamento e descrição do padrão de uso e cobertura da terra em municípios do sudoeste goiano, no qual os autores afirmam que a agricultura corresponde a maior área do município de Rio Verde (GO), seguida de áreas de Cerrado/mata e pastagem.

Se o atual Código Florestal Federal (BRASIL, 2012), a Política Florestal do estado de Goiás (GOIÁS, 2013) e o Código Ambiental Municipal de Rio Verde (GO) (RIO VERDE, 2015) forem cumpridos, a tendência é que não ocorram mais perdas e até mesmo tenha incremento de área de vegetação nativa de Cerrado, considerando, neste último caso, a recuperação de áreas degradadas e com uso irregular. Observa-se que a perda de áreas de Cerrado/mata foi menor de 2007 para 2017, em relação aos anos anteriores (Tabela 7; Tabela 11; Tabela 15; Figura 3). Martins et al. (2016) observaram resultados para a microrregião Sudoeste de Goiás parecidos, proporcionalmente, com os obtidos na bacia do ribeirão da Laje ao afirmarem que as áreas cobertas por vegetação 
remanescente permanecem, relativamente, estáveis desde 1995, com decréscimo de, aproximadamente, $3 \%$.

A cobertura vegetal natural é um importante indicador das condições ambientais de uma unidade territorial (de uma bacia hidrográfica, por exemplo) propiciando proteção ao solo, reduzindo o transporte de sedimentos e o assoreamento dos corpos d'água, serve de habitat para animais silvestres (NEVES et al., 2014), além de contribuir para o equilíbrio do agroecossistema (como, por exemplo, abriga inimigos naturais, favorece a recarga de água na bacia hidrográfica, que é importante para a produção de alimentos).

O aumento da área urbana ao longo dos anos é em decorrência da demanda por habitação da população do município de Rio Verde (GO) que cresce de forma expressiva. Conforme IBGE (2018c): esse município representa a quarta economia de Goiás, é o principal município da microrregião Sudoeste de Goiás, com uma população que corresponde a quarta maior do estado; a população rioverdense aumentou 83,19\% de 1991 para 2010 , e 14,89\% de 2010 para 2015; passou de 176.424 habitantes, em 2010, para 217.048 habitantes (estimativa), em 2017, ou seja, neste período aumentou $23,03 \%$.

A expansão de área com instalação de indústrias, além de ser devido ao aumento da demanda local e regional, é reflexo também da demanda externa (outros estados e países) por produtos. Na área industrial são observadas empresas de produção de alimentos, além de armazenamento de grãos, comércio de máquinas agrícolas, postos de combustíveis e outras.

O incremento das construções rurais no decorrer dos anos, além de construções de ranchos, é para atender a produção agrícola (construção de balcões, armazéns e outros) e devido às instalações de granjas de aves e suínos para atender a demanda de matéria prima da BRF S. A. No ano de 2017 foi observado um total de 23 granjas de médio e grande porte na área de estudo.

É importante ressaltar que essas indústrias e granjas geram resíduos, sendo que estes precisam ser tratados e destinados de maneira correta, conforme normas e leis específicas, para não causarem contaminação dos solos e das águas e, consequentemente, outros danos ambientais e à saúde pública. É importante ressaltar, ainda, que as áreas degradadas precisam ser recuperadas e que toda a bacia hidrográfica precisa ser constantemente monitorada, em especial quanto aos limites de áreas de preservação permanente (APP) e de reservas legal (RL), para que as leis ambientais sejam cumpridas, dentre elas, as supracitadas.

Assim como os resultados obtidos sobre o uso e cobertura da terra, com o uso de geotecnologias, por Silva e Souza (2012), Fernandes et al. (2014), Seabra et al. (2014), Martins et al. (2016), Almeida et al. (2017), Braz et al. (2017), Campos e Queiroz Filho (2017) e Maranhão et al. (2017) e outros, em diferentes unidades territoriais, que obtiveram resultados importantes para subsidiar o planejamento $e$ a gestão ambiental dessas áreas, os resultados obtidos sobre as mudanças do uso e cobertura da terra na bacia do ribeirão da Laje indicam a necessidade de políticas públicas comprometidas não somente com o desenvolvimento econômico, mas também com as questões ambientais, com um meio ambiente ecologicamente equilibrado.

\section{CONSIDERAÇÕES FINAIS}

O decréscimo observado ao longo dos anos da área de vegetação nativa de Cerrado, em decorrência de um modelo de desenvolvimento fundamentado em uma agropecuária com uso extensivo e intensivo dos solos em busca de ganhos em produtividades, é uma informação importante, assim como o aumento de área urbanizada, industrial e de construção rural, para implementação de políticas públicas condizentes com o desenvolvimento econômico e a sustentabilidade ambiental, principalmente quando se trata de um recurso natural importante para o desenvolvimento econômico e social da região.

É notável a necessidade de planejamento e gestão ambiental nessa bacia hidrográfica e de implementação de programas e/ou ações para a recuperação das áreas degradadas.

Recomenda-se o desenvolvimento de planos de ação de forma a integrar diversos atores sociais ou setores (instituições públicas, privadas e sociedade civil em geral), para a garantia de um ambiente saudável. Essa ação integrada possibilitará a consciência ecológica da sociedade. Ações como educação ambiental e voltadas para o cumprimento das leis ambientais são fundamentais. É importante demostrar aos produtores rurais que as áreas degradadas, além de causarem prejuízos

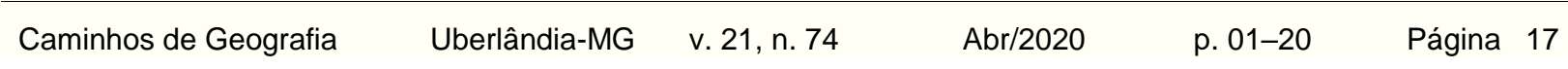


ambientais (como, por exemplo, redução da recarga de água na bacia hidrográfica e assoreamento de cursos hídricos), causam também prejuízos econômicos (como, por exemplo, perda de solos, principalmente da camada mais fértil, e, consequentemente, baixa ou improdutividade e redução do valor da propriedade).

Assim, são necessários o monitoramento e o acompanhamento constante dessa bacia hidrográfica, especialmente das áreas degradadas, de APP e RL, pelos agentes públicos, uma vez que a proteção dos recursos hídricos depende da definição de instrumentos e programas que permitam a valorização das áreas de menor pressão antrópica, a recuperação de áreas degradadas, principalmente em áreas relevantes para a proteção dos corpos de água, como APP, o cumprimento das leis florestais vigentes entre outras ações.

O aumento da demanda da população por alimentos, recursos hídricos e outros recursos naturais, seja em âmbito local, nacional e global, precisa ser atendido com o menor impacto negativo possível ao meio ambiente, de forma a garantir recursos naturais e um ambiente ecologicamente equilibrado para as gerações atuais e futuras.

Estes resultados subsidiarão o planejamento, a gestão ambiental e a recuperação de áreas degradadas na bacia do ribeirão da Laje, contribuído para a garantia quantitativa e qualitativa de um recurso (água) vital para o desenvolvimento econômico e social. É importante ressaltar, ainda, que estão sendo realizados outros estudos (morfometria, fragilidade ambiental, hidrometria e qualidade da água) no intuito de disponibilizar informações holísticas e integradas da unidade territorial em questão.

\section{REFERÊNCIAS}

ALMEIDA, R. P.; FRAZÃO, L. A.; LEITE, M. E.; FERNANDES, L. A. Uso e ocupação do solo em áreas de assentamentos rurais no norte de Minas Gerais. Caminhos de Geografia Uberlândia v. 18, n. 62, p. 13-31, 2017. https://doi.org/10.14393/RCG186202

BRASIL. Presidência da República. Lei № 2.651. Dispõe sobre a proteção da vegetação nativa e dá outras providências. Diário Oficial [da] República Federativa do Brasil. Brasília, DF, 25 de maio de 2012.

BRAZ, A. M.; BRAZ, A. M.; BONI, P. V.; GARCIA, P. H. M.; PINTO, A. L.; OLIVEIRA, I. J. Uso, cobertura e manejo da terra: contribuições teóricometodológicas e subsídios à conservação ambiental na bacia hidrográfica do córrego Ribeirãozinho, Selvíria/MS. Caminhos de Geografia, v. 18, n. 64, p. 310-327, 2017. https://doi.org/10.14393/RCG186424

CAMPOS, P. B. R.; QUEIROZ FILHO, A. P. Matriz de transição na detecção das mudanças do uso e ocupação do solo: estudo de caso do Centro Educacional Unificado da Paz - Zona Norte de São Paulo. Ra'eGa, v.42, p. 225 -238, 2017. https://doi.org/10.5380/raega.v42i0.47694

EMBRAPA. Sistema Brasileiro de Classificação de Solos. Embrapa Produção de Informação: Brasília, 2013. 353 p.

FERNANDES, F. H. S.; MOREIRA, A. A.; NERY, C. V. M. Dinâmica do uso e ocupação do solo da área desapropriada do lago artificial do bico da pedra no norte do estado de Minas Gerais. Caminhos de Geografia, v. 15, n. 50, p. 187-206, 2014.

GOIÁS (Estado). Lei n. ${ }^{\circ} 18.104$, de 17 de julho de 2013. Dispõe sobre a proteção da vegetação nativa, institui a nova Pólítica Florestal do Estado de goiás e dá outras providências. Disponível em: <http://www.gabinetecivil.go.gov.br/leis_ordinarias/2013/lei_18104.htm>. Acesso em: 27 fev. 2018.

IBGE - Instituto Brasileiro de Geografia e Estatística. Projeção da população do Brasil por sexo e idade para 0 período 2000/2060. 2013. Disponível em: <ftp://ftp.ibge.gov.br/Projecao_da_Populacao/Projecao_da_Populacao_2013/nota_metodologica_201 3.pdf >. Acesso em: 09 fev. 2018.

$\begin{array}{lllll}\text { Estimativas da população residente no Brasil e unidades da federação com data de } \\ \text { referência } \\ \text { em } & \text { 10 } & \text { de julho } \text { de } 2017 . & 2017 . & \text { Disponível em: }\end{array}$

$\begin{array}{lllll}\text { Caminhos de Geografia } \quad \text { Uberlândia-MG } & \text { v. 21, n. } 74 & \text { Abr/2020 } & \text { p. 01-20 } & \text { Página } 18\end{array}$


<ftp://ftp.ibge.gov.br/Estimativas_de_Populacao/Estimativas_2017/estimativa_TCU_2017_20180207. pdf>. Acesso em: 10 fev. 2018.

Brasil. População 2017 (estimativa). 2018a. Disponível em:

$<$ https://cidades.ibge.gov.br/brasil/panorama>. Acesso em: 25 fev. 2018.

Brasil/Estado de Goiás. População 2017 (estimativa). 2018b. Disponível em: <https://cidades.ibge.gov.br/brasil/go/panorama>. Acesso em: 25 fev. 2018.

. Cidades. Disponível em: < https://cidades.ibge.gov.br/>. Acesso em: 27 fev. 2018c.

LANDIS, J. R.; KOCH, G. G. The measurement of observer agreement for categorical data. Biometrics, Arlington, v.33, n.1, p.159-174, mar. 1977. https://doi.org/10.2307/2529310

MARANHÃO, D. D. C.; PEREIRA, M. G.; COSTA, E. M; ANJOS, L. H. C. Correção de imagens e caracterização do uso da terra no município de pinheiral, estado do Rio de Janeiro, Brasil. Caminhos de Geografia, v. 18, n. 62, p. 174-188, 2017. https://doi.org/10.14393/RCG186214

MARTINS, A. P; SCOPEL, I. SOUSA, M. S.; PEIXINHO, D. M. Uso da terra e cobertura vegetal de 1985 a 2015 no Sudoeste de Goiás e relação com o meio físico. In: PEIXINHO, D. M; SOUSA, M. S. Reconfiguração do Cerrado: uso, conflitos e impactos ambientais. Goiânia: Gráfica UFG, 2016. 11-33 p.

NEVES, L. F. S; NEVES, S. M. A. S.; CANELA, G. R. Análise da fragmentação de Cerrado na bacia hidrográfica do rio Aguapeí, Porto Esperidião (MT): um estudo de caso a partir das geotecnologias e métricas da paisagem. Ateliê Geográfico, v. 8, n. 2, p.130-149, 2014. https://doi.org/10.5216/ag.v8i2.21557

OLIVEIRA, E. G.; MIZIARA, F.; FERREIRA, M. E. Fatores determinantes e cenários futuros sobre a expansão da cana-de-açúcar na região de Cerrado no Centro-Oeste mineiro. Ateliê Geográfico, v. 9, n. 1, p.79 - 103, 2015. https://doi.org/10.5216/ag.v9i1.29101

ONUBR-Organização das Nações Unidas no Brasil. Apesar de baixa fertilidade, mundo terá 9,8 bilhões de pessoas em 2050. 2017. Disponível em: <https://nacoesunidas.org/apesar-de-baixafertilidade-mundo-tera-98-bilhoes-de-pessoas-em-2050/>. Acesso em: 10 fev. 2018.

PEEL, M.C., FINLAYSON, B.L., MCMAHON, T. A. Updated world map of the Köppen-Geiger climate classification. Hydrology and Earth System Sciences, v. 11, p. 1633-1644, 2007. https://doi.org/10.5194/hess-11-1633-2007

PESSÔA, V. L. S. Ação do estado e as transformações agrárias no cerrado das zonas de Paracatu e Alto Paraíba. 239f. Tese (Doutorado em Geografia). Universidade Estadual Paulista, Rio Claro, 1988.

PONTIUS JUNIOR. R. G.; SHUSAS, E.; MCEACHERN, M. Detecting important categorical land changes while accounting for persistence. Agriculture, Ecosytems \& Environment, v. 101, p. 251-268, 2004. https://doi.org/10.1016/i.agee.2003.09.008

PRADO, R. B. FERREIRA, C. E. G. BENITES, V. M. NAUMOV, A. Mapeamento e descrição do padrão de uso e cobertura da terra em municípios do sudoeste goiano a partir de imagens orbitais TM/Landsat-5. Embrapa Solos, Boletim de pesquisa 148, 2009, 54p.

RIO VERDE (Município). Lei 5.090/2005. Institui o Código Ambiental Municipal e dá outras providencias: promulgada em 28 de dezembro de 2005. Rio Verde, 2005. Disponível em: < http://www.rioverdegoias.com.br/arquivos/lei5090.pdf>. Acesso em: 29 jun. 2016.

ROSA, R. 2005. Geotecnologias na Geografia Aplicada. Revista do departamento de geografia, Uberlândia, v. 16, p. 81-90, 2005. https://doi.org/10.7154/RDG.2005.0016.0009

ROSENFIELD, G. H.; FITZPATRICK-LINS, K. A coefficient of agreement as a measure of thematic classification accuracy. Photogrammetric Engineering and Remote Sensing, v.52, n.2, p.223-227, 
1986.

SEABRA, V. S.; XAVIER, R. A.; DAMASCENO, J. DORNELLAS, P. C. Mapeamento do uso e cobertura do solo da bacia do rio Taperoá: Região semiárida do estado da Paraíba. Caminhos de Geografia, v. 15, n. 50, p. 127-137, 2014.

SIEG - Sistema Estadual de Geoinformação de Goiás. Downloads/SIG - Shapefiles. Disponível em: <www.Sieg.go.gov.br>. Acesso em: 30 ago. 2017.

SILVA, E. B.; SOUZA, J. C. Modernização da agricultura e apropriação do Cerrado: uma análise das microrregiões do Sudoeste Goiano e Quirinópolis no Estado de Goiás. In: 21ํㅡㄹ Entro Nacional de Geografia Agrária, Uberlândia. Anais... Uberlândia: AGB-ENGA, 2012, 14 p.

SIMÕES, L. B. Integração entre um modelo de simulação hidrológica e sistema de informação geográfica na delimitação de zonas tampão ripárias. Tese (Doutorado em Agronomia/Energia na Agricultura) - Faculdade de Ciências Agronômicas, Universidade Estadual Paulista, Botucatu, 2001.

SNIS-Sistema Nacional de Informação sobre Saneamento. Série Histórica/Diagnóstico anual de água e esgotos. Disponível em: <http://www.snis.gov.br/diagnostico-agua-e-esgotos>. Acesso em: 29 abr. 2018.

SOUZA, J. R.; REIS, L. N. G.; PEDROSA, A. S. Caracterização e susceptibilidade ecológica dos fragmentos florestais nas bacias do ribeirão Douradinho e ribeirão Estiva - Minas Gerais. Caminhos de Geografia, v. 15, n. 51, p. 85-94, 2014.

UN-United Nations, Department of Economic and Social Affairs, Population Division (2017). World Population Prospects: The 2017 Revision, Key Findings and Advance Tables. SA/P/WP/248. Disponível em: <https://esa.un.org/unpd/wpp/Publications/Files/WPP2017_KeyFindings.pdf>. Acesso em: 10 fev. 2018. https://doi.org/10.18356/b19523c6-en

Recebido em: 19/05/2018

Aceito para publicação em: 09/04/2020 